\title{
Synthesis and optical properties of hybrid and alloy plasmonic nanoparticles
}

\author{
Michael B Cortie* and Andrew M. McDonagh
}

Institute for Nanoscale Technology, University of Technology Sydney, PO Box 123, Broadway, NSW 2007

*corresponding author, michael.cortie@uts.edu.au

\section{RECEIVED DATE}

TITLE RUNNING HEAD : Optical properties of hybrid nanoparticles

\section{Contents}

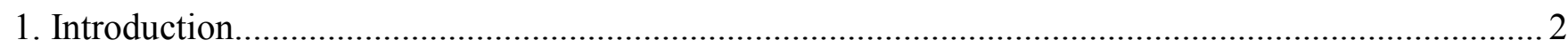

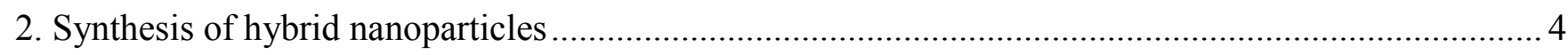

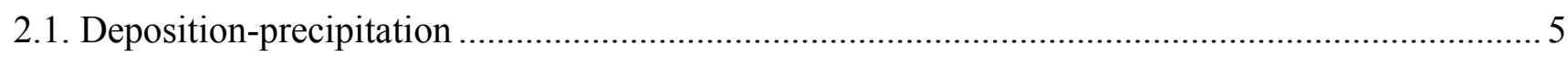

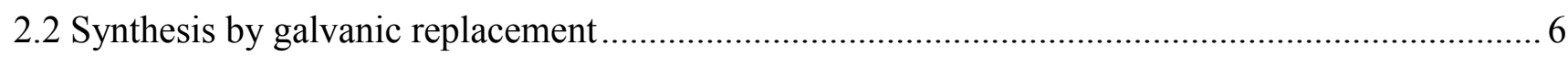

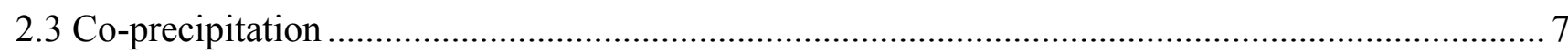

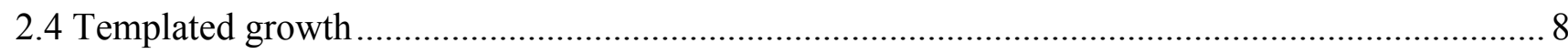

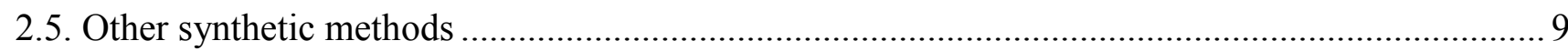

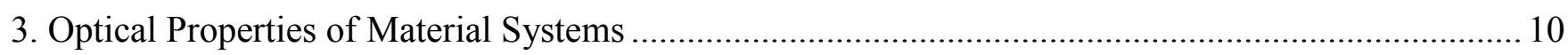

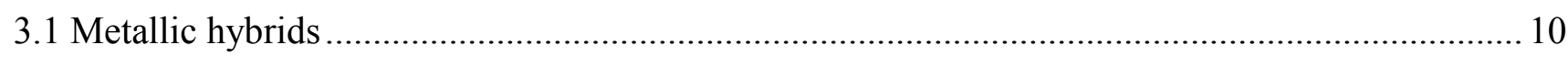

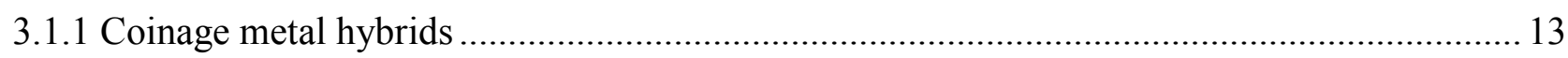

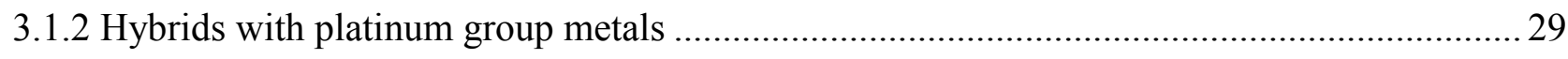

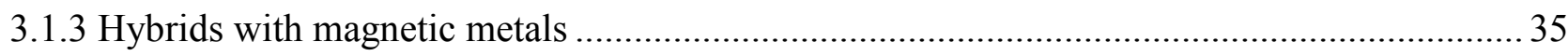

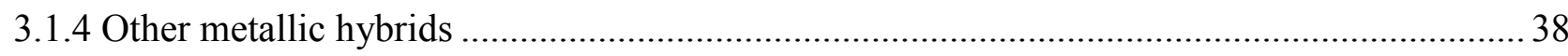

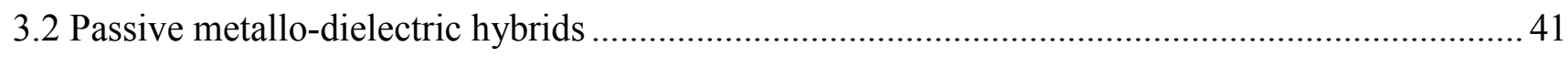

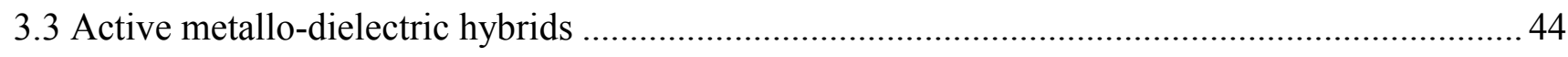

3.3.1 Modulation of plasmon resonance by metal-insulator transitions .......................................... 44

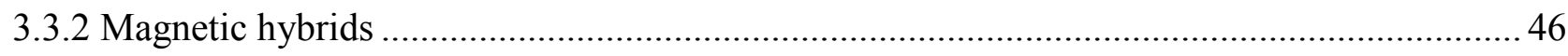

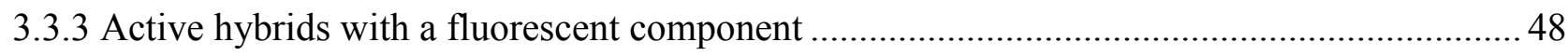

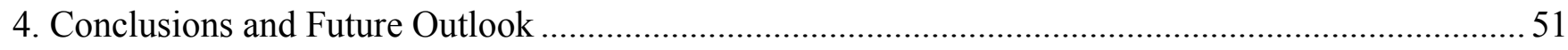

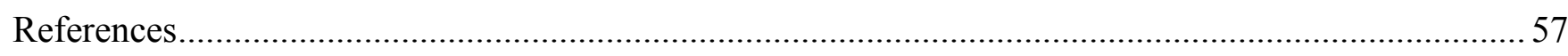




\section{Introduction}

The plasmon resonances and other optical properties of elemental noble and alkali metal nanoparticles have generated enormous scientific interest. ${ }^{1-11}$ There are numerous applications for plasmon-active nanoparticles especially in areas such as biological microscopy, medicine, and sensors. ${ }^{12-18}$ The various applications exploit some aspect of the plasmon resonance, which include particle-particle plasmon interactions, ${ }^{19}$ the unusual coloring or dichroic effects in isolated particles, ${ }^{20-21}$ light-induced plasmonic heating, ${ }^{22}$ light scattering, ${ }^{23}$ or two-photon phenomena. ${ }^{24}$ Hybrid or multifunctional nanoparticles constructed from more than one component phase have also been attracting increasing interest due to their additional functionalities. ${ }^{25-30}$ In this review we consider specifically the optical properties of solid nanoparticles comprised of more than one phase or compound. Alloyed nanoparticles (solid solutions or intermetallic compounds of the metallic elements) are also included because these intergrade with the two-phase hybrids. The primary focus here is the optical properties related to plasmonic phenomena. We exclude nanoparticle hybrids between solid cores and organic ligands, or between solid cores and proteins and other large organic molecules, from the scope of the review as, in most cases, the only effect the organic substance has on the optical properties is to impart a small bathochromic shift ('redshift') to the plasmon resonance.

The term 'hybrid nanoparticle' is commonly used to describe a discrete multi-component nanoparticle. This particular nomenclature has been in use since at least $1999,{ }^{31}$ but multi-component nanoparticles of various kinds had been studied long before then. For example, the phenomenon of magnetic exchange bias was first reported in 1956 for $\mathrm{Co} @ \mathrm{CoO}$ nanoparticles of 10 to $100 \mathrm{~nm}$ diameter. ${ }^{32}$ In this review, we have concentrated on results published from 2005 onwards but some important earlier work is also mentioned in order to provide a historical context.

There are a number of important reasons why more than one phase, compound or other constituent might be gainfully fused to make a composite nanoparticle. For example, the surface chemical 
properties of a core particle can be modified by coating with a second material to provide improved colloidal stability or resistance to oxidation, or additional functionality may also be imparted to a nanoparticle by attaching an antibody, for example, to enable biological targeting. Here, however, we are most interested in the plasmon resonances of hybrid nanoparticles, so those instances in which an interaction between the two components of the hybrid results in an active enhancement or modulation of the plasmon resonance are especially relevant. Information on the many other interesting chemical and physical properties of conjugates with organic molecules may be found elsewhere. ${ }^{5,12,14-17}$

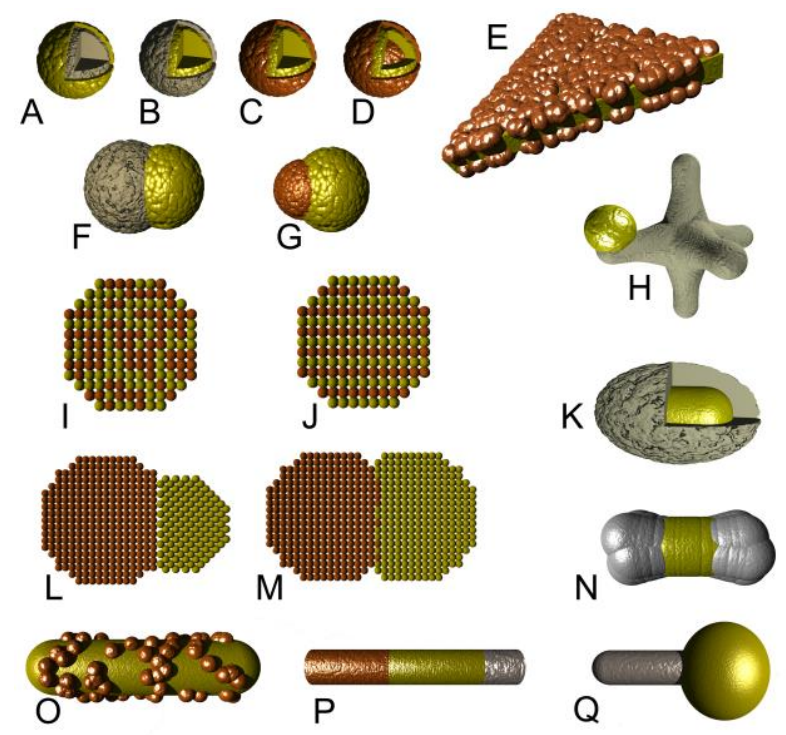

Figure 1. Examples of hybrid nanoparticles, (a) dielectric@metal core-shell, (b) metal@dielectric core-shell, (c) metal@metal core-shell, (d) metal@metal@metal core-shell, (e) metallic nano-triangle with overcoat of second metal, (f) heterodimer comprised of dielectric and metal parts, $(\mathrm{g})$ heterodimer comprised of two different metal parts, (h) semiconductor crystal with attached metal nanosphere, (i) cross-section through alloyed metal nanoparticle showing disordered nature of atomic occupancies, (j) cross-section through nanoparticle comprised of an intermetallic compound showing ordered atomic occupancy, (k) metal nanorods coated in a thick shell of dielectric, (l) dimer with incoherent crystalline interface between the parts, $(\mathrm{m})$ dimer with coherent interface between the parts, (n) nanorods with overgrowth of another metal at the rod ends, (o) nanorods with a sparse overgrowth of a second metal, (p) segmented nanowires or nanowire comprised of two or more elements, (q) 'nano-tadpole'. 
There are many different possible types or morphologies of hybrid nanoparticle, some of which are depicted schematically in Figure 1. Here we have chosen to group the possibilities into three groups, defined not by shape but rather by how the optical properties of the parts interact. In the first type, which will be termed 'metallic' hybrids, the entire nanoparticle is comprised of electron-conductive materials, but the overall composition contains more than one element. The nanoparticle might be single phase, or a composite of two or more phases of differing crystal structure or composition.

The second type of hybrid nanoparticle is comprised of at least one metallic and one dielectric phase, but the only effect of the dielectric phase on the particle's plasmon response is to red-shift it by passively increasing the local refractive index adjacent to the metallic part of the particle. These hybrid nanoparticles will be termed 'passive metallo-dielectric' hybrids. Of course the dielectric may exert other useful functions, such as provide corrosion protection or solvent compatibility to the metallic part, or be magnetic or fluorescent. Conversely, this category also includes hybrids where the only purpose of the metallic part is to provide corrosion protection or electrical conductivity to the dielectric part. The dielectric may be a semi-conductor or insulator, inorganic or organic, but has four defining features 1) it is not a metal, 2) it is clearly part of the nanoparticle, 3) it is a solid phase, and 4) its functionality does

not interact with the plasmon resonance of the metallic part except as discussed above. Most existing colloidal nanoparticles fall into this class, if only by virtue of the fact that many are coated with a shell of adsorbed molecules.

The third type to be considered consists of nanoparticles comprised of at least one metallic and one dielectric phase, but where the composite particle has some active optical functionality lacking in its individual parts. These will be termed 'active metallo-dielectric' hybrids.

\section{Synthesis of hybrid nanoparticles}

The individual components of a hybrid nanoparticle often possess different surface properties, crystal 
lattices, redox potentials, crystal morphologies, or surface charge, so the successful combination of these materials into a discrete composite hybrid nanoparticle presents some synthetic challenges. Costi et al. $^{25}$ described how the processes of nucleation and growth may be used to prepare hybrids, while Ferrando et al. ${ }^{11}$ provided a comprehensive overview of the methods available for purely metallic particles. Reviews of the methods required to make single or hybrid nanoparticles with a magnetic component have also appeared. ${ }^{29,33}$

The nature of the interface between the two or more parts is an important consideration. Examples of epitaxial hetero-structured hybrids as well as particles in which the interface has no lattice correspondence or orientation relationship have been observed. ${ }^{25}$ Furthermore, the geometry of the hybrid can vary from a simple spherical core-shell, to heterodimers (or 'dumbbells'), through to nanorods, cubes or more complex shapes, Figure 1. Dielectric-dielectric systems in which a controlled transition of interface between coherent (continuous lattice correspondence) to incoherent (no lattice correspondence) occurs as the lattice mismatch of the system is increased are also known. ${ }^{34}$ In general, however, a low surface energy mismatch between the components is helpful in securing a solid-solid hybrid.

In this section we summarize the synthetic techniques that may be used to prepare hybrid nanoparticles with two components, designated Part 1 and Part 2. Note that these synthetic principles can be extended to produce more complex, multi-component structures, if desired.

\subsection{Deposition-precipitation}

In this strategy, the first component of the nanoparticle (Part 1) is first produced separately by some appropriate mechanism, such as nucleation and growth by reduction, or by $\mathrm{pH}$ change of a solution, or pyrolysis of an appropriate precursor. It is generally useful to produce a particle size distribution that is as monodisperse as possible at this point and the reader is referred to existing literature for some 
reviews of the various methods of synthesis. ${ }^{4,27,35}$ Next, the reaction environment is changed so that a second component (Part 2) can precipitate onto the first. Part 2 will often nucleate and grow on Part 1 to produce composite nanoparticles because, in general, heterogeneous nucleation is more favorable than homogenous nucleation. This is because the availability of an existing surface on which to nucleate a nanocrystal lowers the free energy barrier considerably. ${ }^{36}$ The precipitation of $\mathrm{Au}$ onto $\mathrm{CdSe}^{25}$ or $\mathrm{Ag}$ onto a $\mathrm{Fe}_{2} \mathrm{O}_{3}$ core, ${ }^{37}$ are examples of this method. In some cases irradiation with light can accelerate or control the process. ${ }^{25}$

\subsection{Synthesis by galvanic replacement}

In this synthetic strategy, a nanoparticle of a moderately active metal, such as $\mathrm{Ag}$ or $\mathrm{Co}$, of appropriate shape and size is produced and then the reaction environment is changed to introduce a solution of a more noble metal, such as $\mathrm{Au}$. The more noble metal precipitates onto, and begins to consume the more active core material by galvanic displacement. If the process is allowed to proceed to completion, the product could be a hollow, single phase, Part 2 nanoparticle, Figure 2, but the process can be halted before completion to produce a hybrid core-shell or alloy nanoparticle. Although the noble metal might be expected to precipitate on the outside of the core nanoparticle and work its way inwards with time, in some cases a surprising inversion occurs. In the case of $\mathrm{Au}$ reacting with InAs nanoparticles, the Au diffuses rapidly to the interior of the dielectric nanocrystal to form a well-defined core, while the displaced InAs forms a shell of amorphous InAs or, if oxidized, $\operatorname{In}_{2} \mathrm{O}_{3} \cdot{ }^{38}$ Galvanic displacement will often occur during the preparation of hybrid metal-metal nanoparticles from aqueous solution but is not always recognized by the corresponding authors.

There are at least two mechanisms by which a hollow particle could be formed. For example, the Kirkendall effect (in which porosity is generated when the rate of solid state diffusion of one of the elements is faster than that of the others) can be invoked to explain how an $\mathrm{Ag} @ \mathrm{Au}$ particle can be hollowed out in a purely solid state process (because Ag diffuses about twice as fast as $\mathrm{Au}^{39}$ ). 
Alternatively, if the $\mathrm{Au}$ shell is not continuous and the hybrid particle is in an aqueous environment, then a redox-mediated corrosion process, in which the Ag-rich regions are anodic relative to the Au-rich regions, can be envisaged.

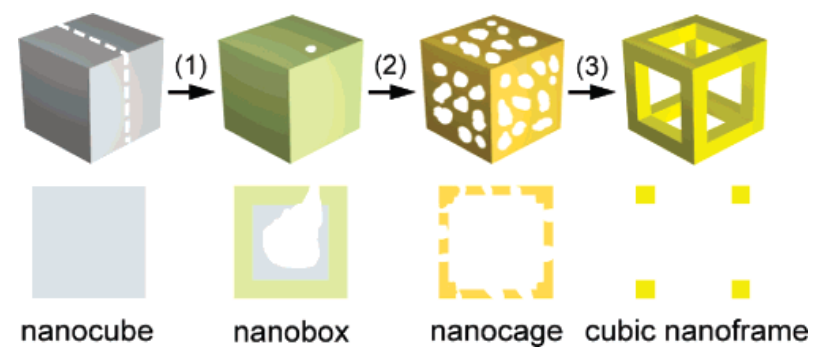

Figure 2. The process of galvanic displacement, $\mathrm{Au}$ for $\mathrm{Ag}$, can be used to convert a template to alloyed boxes or cages, or even a hollow frame. (Reprinted with permission from ref ${ }^{40}$ Copyright 2007 American Chemical Society.)

A conceptually similar process involves making the Part 1 nanoparticle core, and then partially reacting it to form a shell of metal, ${ }^{41}$ sulfide $^{42}$ or oxide. ${ }^{43}$ Alternatively, a Part 1 core (e.g., Au) can be coated with a sacrificial material (e.g., Ag), which is subsequently completely converted to a third phase, such as $\mathrm{Ag}_{2} \mathrm{Se}^{44}$ It is also possible to coat the core with some precursor $\left(\mathrm{PdCl}_{2}\right.$, for example $\left.{ }^{45}\right)$ and allow the Part 2 phase to form from that by thermal decomposition.

\subsection{Co-precipitation}

The co-precipitation method produces hybrid particles in one-step by simultaneous nucleation and growth. Solution conditions are chosen to allow Part 1 and Part 2 to precipitate simultaneously and, ideally, the two parts should heterogeneously nucleate on one another to form a composite particle. In practice, however, co-precipitation of true hybrids is not readily achieved. In the case of metallic components, this is because the redox potential for each reduction reaction is different, so in general the more noble element is reduced first followed by the other elements. One way to overcome this is to use 
a very strong reductant such as borohydride, so that reduction occurs so rapidly that the usual galvanic processes do not occur to a significant extent. Even in this case, however, the nanoparticles might still precipitate separately ${ }^{46}$ even if simultaneously. Nevertheless, co-precipitation has been used to prepare hybrid nanoparticles of $\mathrm{Au}$ and $\mathrm{Ag},{ }^{47-48}$ as well as $\mathrm{Ag} / \mathrm{AgBr}{ }^{49}$ nanoparticles.

\subsection{Templated growth}

Nanoparticles of triangular or semi-shell form can be produced in small quantities by physical vapor deposition (PVD) onto a suitable template ${ }^{50}$ followed, if necessary, by release, ${ }^{51}$ Figure 3. A hybrid particle can be produced by periodically changing the composition of the deposited material (by changing sputter targets, for example). $\mathrm{Au}-\mathrm{ZnO}$ or $\mathrm{Au}-\mathrm{Al}_{2} \mathrm{O}_{3}-\mathrm{Au}$ nanoparticle sandwiches have been prepared by this means. ${ }^{52-53}$ In the case of templates made of colloidally crystallized spheres, if the nanoparticles are to be released the deposition should proceed at an acute angle, so that the equatorial girths of the semi-shells do not fuse. ${ }^{51}$

The use of porous alumina templates to prepare hybrid nanoparticles has also been explored. A succession of metals, such as Au followed by Pt for example, can be deposited in the pores of the alumina using electrolysis, ${ }^{54-55}$ followed by dissolution of the template to produce free hybrid

nanocylinders or nanowires. ${ }^{56-57}$ Deposition on or into a template is a flexible approach but has the disadvantage that the diameter of rods produced is generally over $50 \mathrm{~nm}$. Particles of this size tend to scatter rather than absorb light, which may not be a desired optical property. In one ingenious development of the technique, metallic components were deposited onto templates of polymer pillars themselves produced by soft lithography, and after some further processing, layers containing hybrid metallic nanorings were produced by microtoming. ${ }^{58}$ 

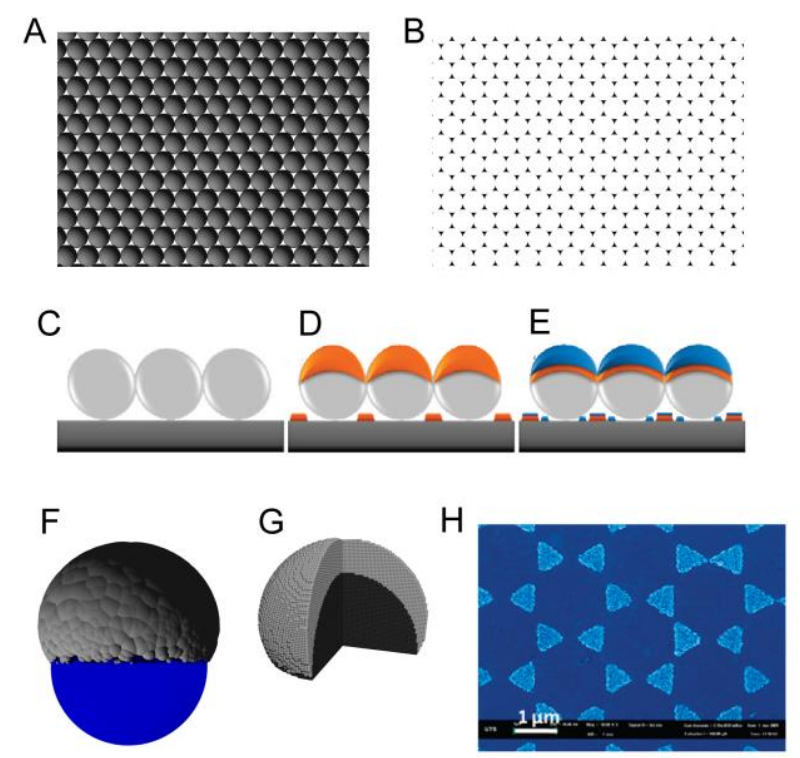

Figure 3. Physical vapor deposition and nanosphere lithography may be used to prepare nanoscale semishells and nano-triangles or nano-bowties. First (a) a template of polymer nanospheres is laid down as a colloidal crystal monolayer; this has a hexagonal pattern of holes (b). One or more layers of metal and dielectric is deposited (c) to (e). The semi-shells (f) that are released by dissolution of the template have tapered walls, $(\mathrm{g}) .^{59}$ Alternatively, the process can be used to prepare arrays of nanotriangles or nano-bowties, (h). (Images $\mathrm{C}$ to $\mathrm{E}$ and $\mathrm{H}$ reprinted with permission from ref ${ }^{52}$. Copyright 2008 American Chemical Society. Image G reprinted from ref. ${ }^{59}$ with permission of the Institute of Physics, London)

\subsection{Other synthetic methods}

Zepto- to atto-mole quantities of hybrid nanoparticles can be produced by electron beam lithography, possibly in combination with physical vapor deposition. ${ }^{60}$ Because of the small quantities produced, this technique appears to be best suited for the production of fixed arrays or chains of hybrid nanoparticles for very precise plasmonic circuitry or lab-on-chip type applications. Electron beam lithography offers excellent top-down control but only relatively small quantities of particles are produced. Other methods include laser ablation, electrochemical, ${ }^{61}$ arc discharge, ${ }^{62}$ sonochemistry followed by galvanic 
displacement, ${ }^{63}$ and radiolytic reduction, ${ }^{64}$ (see also references contained within the various reviews cited previously $\mathrm{y}^{3-5,11,25,27}$ ).

\section{Optical Properties of Material Systems}

\subsection{Metallic hybrids}

Hybrid metallic nanoparticles are of considerable commercial interest as heterogeneous catalysts. Core-shell particles or other hybrids of $\mathrm{Pt}, \mathrm{Ru}, \mathrm{Au}, \mathrm{Pd}, \mathrm{Co}$ and $\mathrm{Cu}$ are amongst the combinations that have been investigated with this application in mind. ${ }^{65-70}$ A comprehensive review of metallic hybrid nanoparticles in general is available and details of the many synthesis techniques and metallic systems of these so-called "nanoalloys" may be found there. ${ }^{11}$ The optical properties of metallic alloys and intermetallic compounds in general was also recently reviewed. ${ }^{10}$ Here, we specifically consider the intersection of these two themes, in particular, studies into the plasmonic optical properties of hybrid nanoparticle systems. However, the diversity of possible metal-metal structures, Figure 1, should be considered, as structure has a significant effect on optical properties

$\mathrm{Au}$ and $\mathrm{Ag}$ are the most frequently mentioned materials in the context of the optical properties of metallic hybrid nanoparticles. This is for two reasons.

The first is that the optical properties of these elements are well suited for sustaining a plasmon resonance in the visible region of the spectrum. If the dielectric function, $\varepsilon$, of the material is written as

$$
\varepsilon(\omega)=\varepsilon_{1}(\omega)+i . \varepsilon_{2}(\omega)
$$

where $\omega$ is the frequency of the incident light, then a localized plasmon resonance is achieved in small nanospheres in vacuum when $\varepsilon_{1}=-2,{ }^{71}$ which for $\mathrm{Au}$ and $\mathrm{Ag}$ is in the green and blue parts of the spectrum respectively. However, the corresponding values of $\varepsilon_{2}$ are also important. It has been shown that the quality factor of the resonance in a nanosphere or nanoshell is proportional to $-\varepsilon_{1} / \varepsilon_{2}$, while that of an ellipsoid is better approximated by $\left(\varepsilon_{1}\right)^{2} / \varepsilon_{2}$, so the lowest possible values of $\varepsilon_{2}$ are desired at the 
wavelength of plasmon resonance. ${ }^{72}$ The dielectric functions of some of the candidate elements are compared in Figure 4.

The second reason for the popularity of $\mathrm{Au}$ and $\mathrm{Ag}$ is that these two elements, and particularly $\mathrm{Au},{ }^{73}$ can be readily formed into nanostructures by chemical, physical and lithographic methods. They are, however, certainly not the only possible material choices. Nanoparticles of $\mathrm{Cu}$ and $\mathrm{Al}$, and the alkali metals, are also capable of sustaining a strong plasmon resonance, ${ }^{10,74-78}$ but are far less studied due to their chemical reactivity and hence difficulties in their preparation and application. Most of the other elements, however, have somewhat damped plasmon resonances. ${ }^{10}$

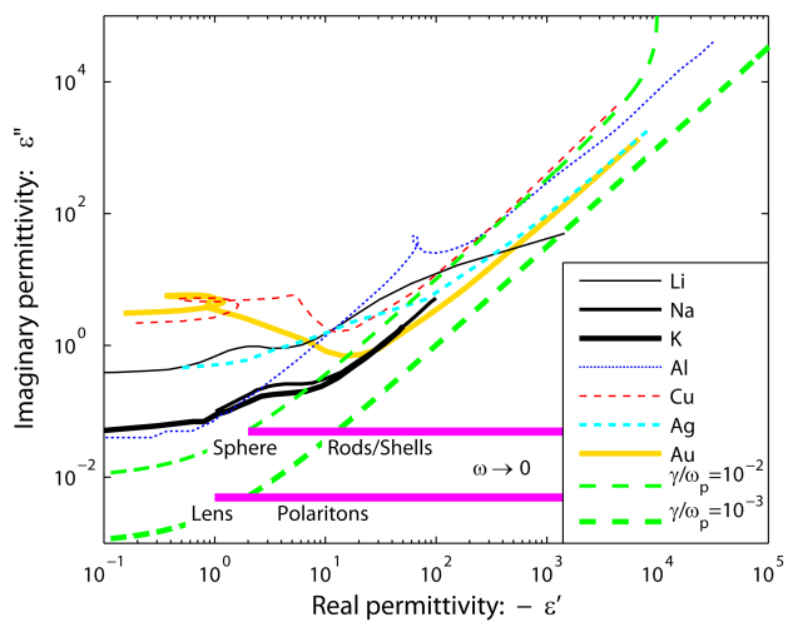

Figure 4. Dielectric functions of a variety of metals that can undergo a strong plasmon resonance. Two Drude models (dashed lines, green) are superimposed on the data. Potassium and aluminum are superior to $\mathrm{Au}$ or $\mathrm{Cu}$ for nanospheres and plasmonic lenses (which require $\varepsilon_{1}<-4$ ), because in that region they have smaller $\varepsilon_{2}$, however, at lower frequencies of light, gold and silver become the better choice. This optimization can be realized in nanoshells and nanorods of Au or Ag because their plasmon resonances are displaced to lower frequencies and hence more negative values of $\varepsilon_{1}$. Reproduced from ref..$^{72}$ by permission of the Optical Society of America.

An interesting aspect, which we consider here, is that of the optical properties of hybrid particles made of these constituents. In principle, there are three possible outcomes for such hybrids in an optical 
context: the optical properties of the parts are each still separately identifiable in the hybrid, the optical properties of the constituents merge or are averaged or, thirdly, something new happens. Which of these occurs also depends on whether the constituents form a solid solution or remain as separate phases and on the morphology of the hybrid. If the plasmon resonances of two metallic components merge in a hybrid particle then the formation of a single-phase alloyed particle has probably occurred. ${ }^{11,79-80}$ The result is general and holds even if some minor tendency towards surface segregation of, for example, the less noble element occurs. ${ }^{11,81}$

Importantly, the behavior of the bulk materials with regard to miscibility or phase stability is a poor guide to nanoscale behavior. ${ }^{82}$ For example, Au and Pt are not mutually soluble in the bulk solid state ${ }^{83}$ but the two may form a random solid solution in bimetallic nanoparticles with sufficiently small radii, with $<3 \mathrm{~nm}^{84}$ or $<6 \mathrm{~nm}^{85}$ being reported as the threshold for the transition. A similar result holds for Au and Fe. ${ }^{86}$ The ordered intermetallic compound $\mathrm{Cu}_{3} \mathrm{Au}$ does not form in $\mathrm{Cu} / 25$ at $\%$ Au nanoparticles of $<5 \mathrm{~nm}$ diameter ${ }^{87}$ whereas in the bulk phase this composition would normally be ordered up to $240^{\circ} \mathrm{C} .^{83}$ Instead, these small $\mathrm{Cu} / \mathrm{Au}$ nanoparticles keep the random face centered cubic structure of the high temperature phase. The trend towards greater mutual solubility holds also for nanoparticles of $\mathrm{In} / \mathrm{Sn}$ and $\mathrm{Bi} / \mathrm{Sn}^{88}$ and appears to be a general tendency in bimetallic systems. This result was predicted in 1995 by Monte Carlo modeling: ${ }^{89}$ the alloying effect in a nanoparticle of radius $r$ can be readily explained as being the result of the interplay of the enthalpy of a de-mixing phase transformation (proportional to volume and hence $r^{3}$ ) and the energy required to create a new surface on de-mixing (proportional to $r^{2}$ ). As $r$ shrinks there can be a size at which the $r^{2}$ term dominates, i.e. there will be insufficient energy for de-mixing to overcome surface effects ${ }^{89}$ so the particle stays as a single-phase alloy. The effect is usually greater in sub-nanometer particles. ${ }^{90}$

Other odd behavior seems possible in the intermediate range of nanoparticle sizes. For example $\mathrm{Cu}_{3} \mathrm{Au}$ was reportedly stabilized in nanoparticles of between 20 and $50 \mathrm{~nm}$ diameter to temperatures two or three hundred degrees Celsius higher than those observed in bulk experiments. ${ }^{91}$ Careful work is 
required to resolve these issues due to the difficulty in characterizing the structure of such small particles. In addition, it has been claimed that some of the "core-shell" samples reported in the past are merely mixtures of elemental nanoparticles, ${ }^{92}$ a much more mundane problem! Clearly, this is a complex and not entirely resolved field.

\subsubsection{Coinage metal hybrids}

The coinage metals (Group 11: $\mathrm{Cu}, \mathrm{Ag}$ and $\mathrm{Au}$ ) with a $q \mathrm{~d}^{10}-(q+1) \mathrm{s}^{1}$ electronic configuration, where $q=3,4$ and 5, respectively, all exhibit a face-centered cubic structure as elements. As a result of interband transitions, they tend to absorb light in the higher energy region of the visible spectrum through to the long-wave UV, with the effect being especially well-developed in $\mathrm{Au}$ and $\mathrm{Cu}$ and accounting for the yellow to reddish colors in bulk form. In the form of isolated nanospheres, they have plasmon resonance peaks in typical transparent media at about $550-600,360-400$, and $520 \mathrm{~nm}$ corresponding to $\mathrm{Cu}, \mathrm{Ag}$ and $\mathrm{Au}$, respectively. ${ }^{93-96}$ As hemispherically-capped nanorods of 2:1 aspect ratio the longitudinal plasmon peaks should be observed at 620,500 , and $620 \mathrm{~nm}$, respectively. ${ }^{76}$ The longitudinal resonance of nanorods is increasingly red-shifted as the aspect ratio is increased but their transverse resonance remains at a very similar wavelength as that for isolated nanospheres. There is, however, a wide variation of values cited for the resonance of $\mathrm{Cu}$ nanospheres, including a report that there is no resonance at all in a true sphere due to the strong damping effect of d-band transitions at these wavelengths in $\mathrm{Cu} .^{97}$

\subsubsection{Ag/Au}

Scientific studies into hybrid nanoparticles in the Ag-Au system date back several decades. Morriss and Collins, for example, prepared colloidal Au@Ag particles in 1964, ${ }^{98}$ but all are preceded by a famous technological application: the manufacture of Late-Roman-era dichroic glass, which is colored by the plasmon resonance of cuboidal Ag-Au alloy nanoparticles of 50 to $100 \mathrm{~nm}$ size. ${ }^{99} \mathrm{The} \mathrm{Ag} / \mathrm{Au}$ 
hybrid nanoparticles remain of interest because of the strong plasmon resonances of the constituent elements and the relatively straightforward nature of the chemistry required for their preparation (aqueous chemistry and atmospheric conditions will suffice ${ }^{47-48}$ ). Here we consider $\mathrm{Ag} / \mathrm{Au}$ alloyed nanospheres as well as core-shell particles, nanorods, and other less symmetrical shapes comprised of these two elements.

Modern interest in the synthesis of alloy particles of these two elements dates from the 1970s (see Papavassiliou $^{62}$ or references in Hostetler, ${ }^{81}$ for example) and there have similarly been many investigations of the optical properties of $\mathrm{Au} @ \mathrm{Ag}$ and $\mathrm{Ag} @ \mathrm{Au}$ core-shell particles since the pioneering study of Morriss and Collins in $1964 .^{98,100}$ Interest in composite nanorods of $\mathrm{Ag}$ and $\mathrm{Au}$, however, is a more recent phenomenon, dating from only $2001 .^{101}$

In the bulk form, $\mathrm{Ag}$ and $\mathrm{Au}$ are mutually soluble ${ }^{83}$ and in general they will also tend to form a solid solution in nanoparticles. This was shown in 1976 for $10 \mathrm{~nm}$ particles, ${ }^{62}$ and has been confirmed several times. ${ }^{11,102-104}$ The effect of this is that the plasmon resonance peak of the hybrid nanoparticle can be smoothly interpolated between that of $\mathrm{Ag}(\sim 380 \mathrm{~nm})$ and that of $\mathrm{Au}(\sim 520 \mathrm{~nm})$ by changing the stoichiometry, ${ }^{47-48,80,95,105-108}$ Figure 5. However, the resulting dielectric function is not a simple linear combination of the ingredients. The non-linear optical $\chi^{(3)}$ properties of such particles have also been assessed but were apparently not significantly greater than those of elemental nanoparticles. ${ }^{95,109}$ Interestingly, alloyed shapes other than spheres, such as pentagonal bipyramids ${ }^{110}$, can also be synthesized in this system by appropriate control of the synthesis conditions. 


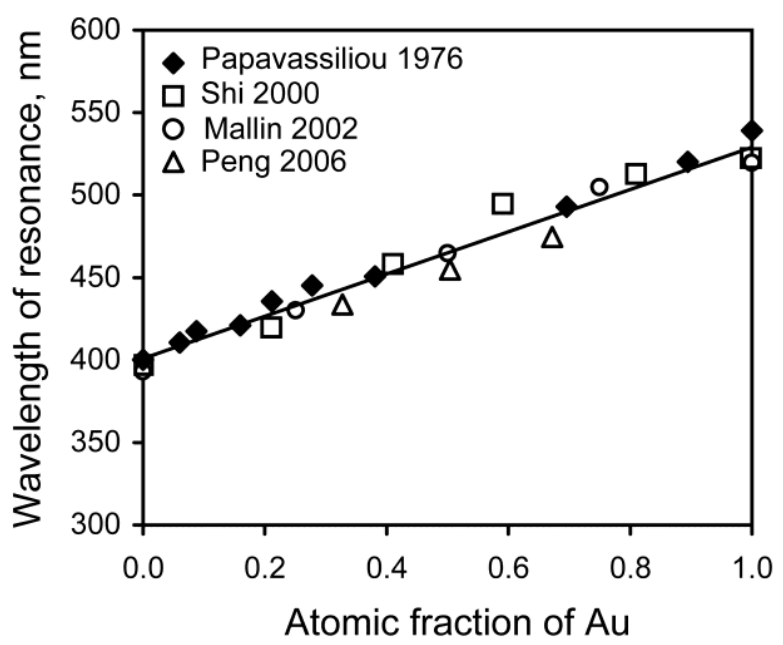

Figure 5. Effect of composition on the surface plasmon resonance of $\mathrm{Ag} / \mathrm{Au}$ alloy nanospheres. Redrawn from the data of Papavassiliou ${ }^{62}$, Shi et al. ${ }^{102}$, Mallin and Murphy ${ }^{47}$ and Peng et al. ${ }^{104}$ The peak extinction wavelength of the data shown here is given by $\lambda(\mathrm{nm}) \approx 401+128 . x$, where $x$ is the atomic fraction of $\mathrm{Au}$ in the $\mathrm{Au}-\mathrm{Ag}$ alloy (note, however, that a non-linear fit has also been suggested in the literature ${ }^{111}$ ).

The optical properties of the core-shell particles are more complex. The theoretical basis for studies into their optical properties was laid by Aden and Kerker in $1951^{112}$ and the issue here is how the two different plasmon resonance frequencies of Ag and Au might interact in the hybrid particle. Au@Ag or $\mathrm{Ag} @$ Au core-shell particles have been prepared by a variety of methods including electrolysis, ${ }^{61}$ radiolysis, ${ }^{105,113-115}$ physical deposition, ${ }^{116}$ or photochemical reduction ${ }^{80,117}$ but sequential chemical reduction in aqueous or organic solutions is also very popular ${ }^{98,100,118-123}$ (see also references provided in Ferrando et al. ${ }^{11}$ ). As a general observation, the plasmon resonance of the core nanosphere is rapidly masked or attenuated by that of the growing shell and, after passing through a regime in which two plasmon resonances are present, the shell resonance dominates. The superior plasmon resonance of $\mathrm{Ag},{ }^{75}$ however, leads to some asymmetry in this process, and the Au resonance is, relatively speaking, more rapidly attenuated or less rapidly developed depending on whether it is in the $\mathrm{Au} @ \mathrm{Ag}$ or the $\mathrm{Ag} @ \mathrm{Au}$ geometry respectively, Figure 6. In the case of $\mathrm{Au} @ \mathrm{Ag}$, the core resonance is blue-shifted until the two resonances merge into a single peak at a rather similar wavelength to that which would have 
been exhibited by a solid particle of $\mathrm{Ag} .{ }^{80,98,120,124}$ For $\mathrm{Ag} @ \mathrm{Au}$, the core resonance is less rapidly attenuated, which produced an extinction spectrum of a somewhat flatter nature. However, one important difference between these metal-metal hybrids and the dielectric@Au or dielectric@Ag nanoshells ${ }^{125}$ is that the strongly red-shifted shell resonances of the latter are generally absent (an interesting exception, Au@Ag@Au multi-shelled particles, will be discussed below). In these systems, the shell generally dominates the optical properties to the extent that the identity of the core is relatively unimportant, as long as it is also metallic and with a similar imaginary part to its dielectric constant to that of the shell. ${ }^{113,121,126}$ The implication of this is that the plasmon resonance of spherical metal-metal core-shell particles can be tuned between the characteristic nanosphere wavelengths of the core and shell materials but not beyond them.
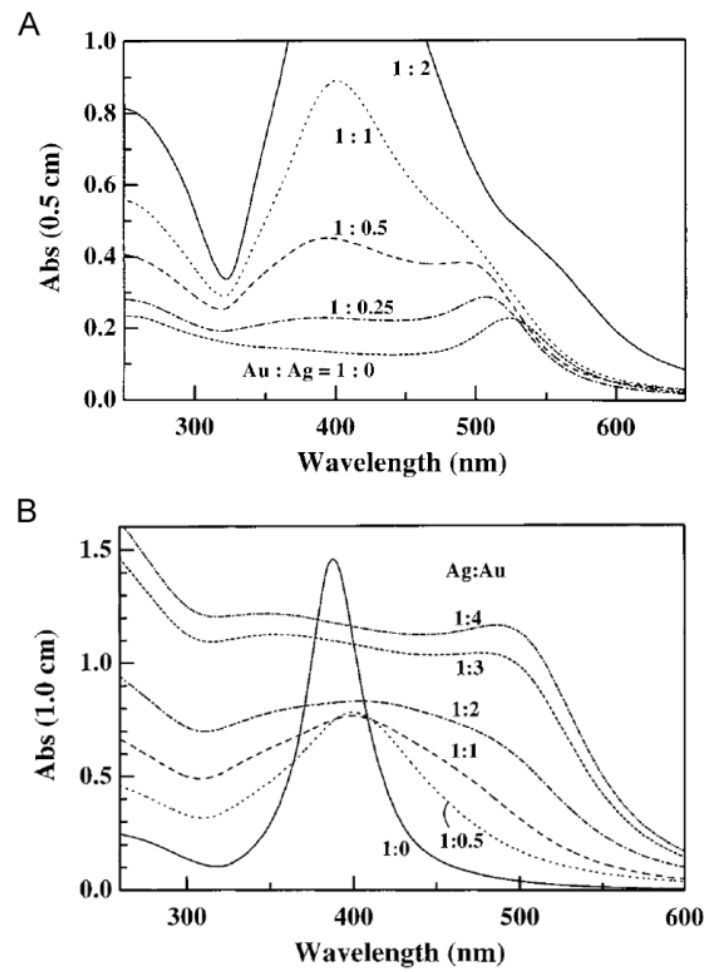

Figure 6. Optical extinction spectra of $\mathrm{Au} @ \mathrm{Ag}$ and $\mathrm{Ag} @ \mathrm{Au}$ core shell particles. (a) The resonance of an Ag shell rapidly overwhelms that of an Au core. (b) The resonance of an Ag core is masked by that of an $\mathrm{Au}$ shell but the effect is not as pronounced as in (a). (Reprinted with permission from ref. ${ }^{114}$ Copyright 2000 American Chemical Society.) 
Given the tendency of $\mathrm{Au}$ and $\mathrm{Ag}$ to alloy, it follows that a hybrid core-shell particle consisting of an elemental core and an alloy shell, ${ }^{121}$ or vice versa, ${ }^{119}$ can also be made. Lee and colleagues, for example, made Ag@AuAg core-shell particles. ${ }^{121}$ The optical properties of their nanoparticles showed a main plasmon resonance assigned to $\mathrm{Ag}$ or $(\mathrm{Au}, \mathrm{Ag})$ (depending on morphology) and a second, weak resonance at about $650 \mathrm{~nm}$. They attributed the latter to Au protrusions nucleating on the surface of the Ag seed and discounted the presence of a hollow core as an explanation (this despite their TEM images ostensibly showing such hollow structures). Heat treatment of $\mathrm{Au} / \mathrm{Ag}$ core-shell particles converts them, as expected, to alloyed nanospheres. ${ }^{114,116}$ This could explain results like those of Jian et al. ${ }^{61}$ who had prepared Au@Ag by electrolysis and found a plasmon resonance in the 445 to $485 \mathrm{~nm}$ range, which is at somewhat higher energy than the usual resonance found by others for Au@Ag. It is probable that this shift in the wavelength of resonance was due to the formation of an alloy rather than to a well-defined Ag shell on a gold core. The photoluminescence properties of the hybrid particle were specifically examined in this latter work, but pure Ag nanoparticles exhibited the strongest emission and the effect was weaker in the hybrid particle.

Tokonami et al. have recently reported a puzzling phenomenon, in which a $\mathrm{Ag}$ shell appears to initially alloy into an existing Au nanoparticle with minimal shift in the plasmon resonance wavelength of the hybrid and with no separate resonant peak due to Ag observed. ${ }^{79}$ Importantly, however, the intensity of the primary Au resonance was initially significantly enhanced by this process, an effect reproduced in other recent work, ${ }^{80}$ Figure 7. Tokonami et al. suggested that the Ag segregates to the core of the particle, leaving the surface of the now larger particle rich in Au. This would not, on the basis of surface energies, have been the expected outcome; since the surface energy of $\mathrm{Ag}$ is less than that of $\mathrm{Au}^{127}$ and some segregation of $\mathrm{Ag}$ on the exterior of the particle would be normally expected if there is time and sufficient thermal activation for diffusion to occur. Nevertheless, because the plasmon resonance of the outer shell in metal-metal core shell particles dominates, this latter scenario would have 
strongly and immediately blue-shifted the resonance of the Au@Ag particle.
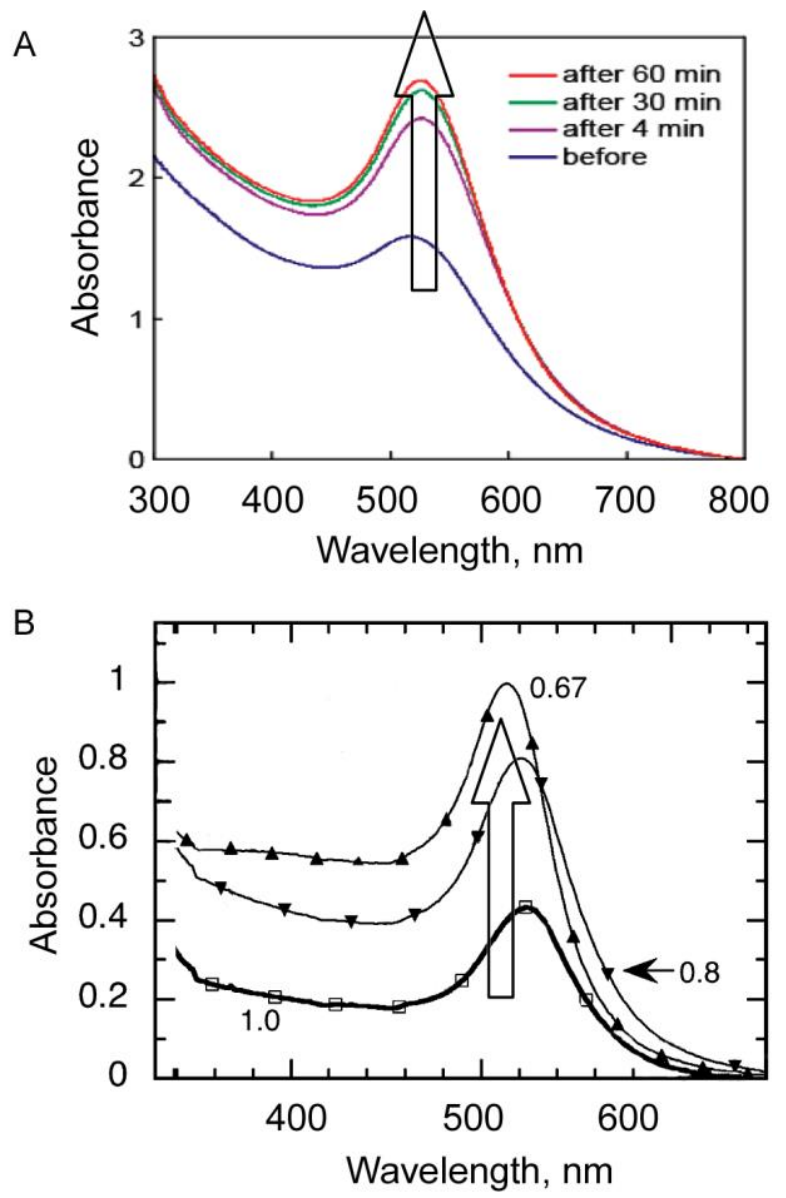

Figure 7. Initial or minor additions of $\mathrm{Ag}$ onto an $\mathrm{Au}$ core have the effect of strongly enhancing the resonance of the Au as indicated by the superimposed arrows. (a) Effect of time on extinction spectrum of $\mathrm{Au}$ nanospheres suspended in $\mathrm{AgClO}_{4}$ solution, ${ }^{79}$ (b) Effect of mole fraction of $\mathrm{Au}$ (indicated by arrows) during photo-reduction of $\mathrm{HAuCl}_{4} / \mathrm{AgNO}_{3}$ precursor solutions. ${ }^{80}$ (Reprinted and modified ${ }^{79-80}$ with permission. Copyright 2009, 2010 American Chemical Society.)

Naturally, multi-shell structures, for example, Au@Ag@Au@Ag can also be formed, and they have quite interesting optical properties. For example, whereas Au@Ag is yellow in color, adding another Au shell to produce Au@Ag@Au gives a blue colloid, ${ }^{100}$ Figure 8, due evidently to the development of a strong plasmon resonance at about $620 \mathrm{~nm}$. The explanation for this new resonance is unclear although the discrepancy was attributed to possible deviation from spherical symmetry in the nanoparticles. 

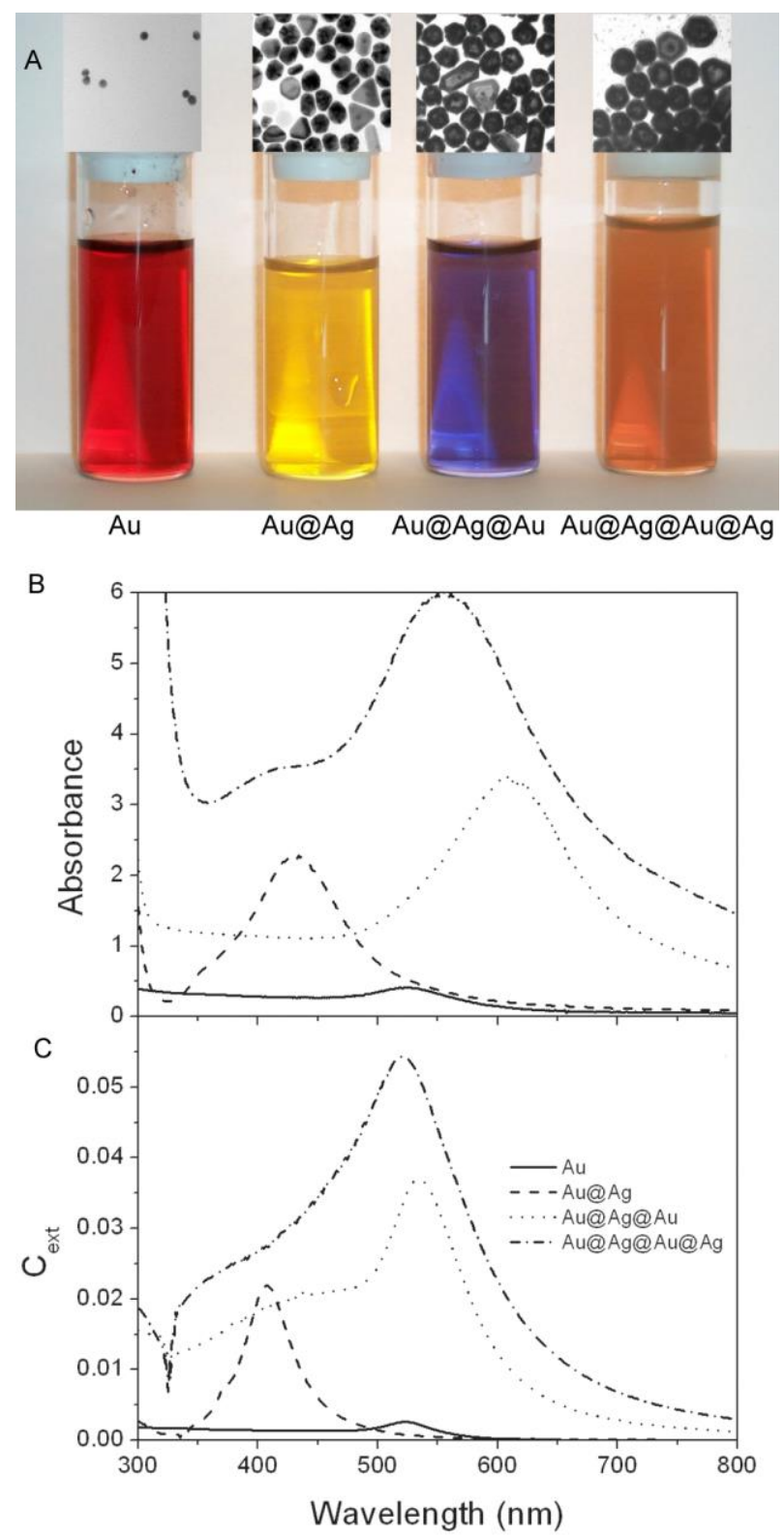

Figure 8. Color changes in multi-shell $\mathrm{Au} / \mathrm{Ag}$ colloids. ${ }^{100}$ (a) Color changes as shells are added. The basic gold colloid is red, but after overcoating with Ag the plasmon resonance is blue shifted and the colloids becomes yellow. A layer of Au, to make Au@Ag@Au, red-shifts the resonance to make a deep blue color, while a further layer of Ag, to make $\mathrm{Au} @ \mathrm{Ag} @ \mathrm{Au} @ \mathrm{Ag}$, red-shifts the resonance again to give an orange color. (b) Measured extinction spectra corresponding to the four types of sample. (c) Simulations of the extinction spectra for the four types of sample. Reproduced by permission of The Royal Society of Chemistry, http://dx.doi.org/10.1039/b500556f. 
The preparation of $\mathrm{Ag} / \mathrm{Au}$ core-shell or alloy particles is now a mature field but there are still a few surprises. For example, Mirkin et al. ${ }^{128}$ studied the effect of prolonged illumination by ordinary fluorescent tube lighting on colloidal suspensions of $\mathrm{Ag} @ \mathrm{Au}$ core-shells and $\mathrm{Ag} / \mathrm{Au}$ alloy nanoparticles and found that, for some stoichiometries, the Ag and Au separated. The Ag formed large, pure nanotriangles and the Au partitioned to sub-5 $\mathrm{nm}$ nanospheres. It was believed that the explanation was related to the inferior oxidation resistance of the $\mathrm{Ag}$, relative to $\mathrm{Au}$ and some additional photochemical effect.

Hollow core-shell nanoparticles with walls comprised of Au-Ag alloy or Au can be prepared by the method of galvanic replacement of an Ag core by Au. ${ }^{129-131}$ The product that forms, either a $\mathrm{Ag} @ \mathrm{Au}$ core-shell or a hollow Au shell, depends on the nature of the supernatant solution, with stronger reducing conditions favoring the core-shell morphology, while an excess of $\mathrm{Au}$ favors complete dissolution of the $\mathrm{Ag}$ to form a hollow particle. However, if the reaction is halted at some intermediate stage, a hollow shape comprised of an Au-Ag alloy is formed. If the template particle was an Ag nanocube $^{132}$ then the final product may be described as a "nano-cage" since the general usage of the term 'nanoshell' in this field is to imply a particle with complete rotational symmetry. The optical properties of this motif are exceedingly tunable, because the aspect ratio, shape and dielectric properties of the nano-cages can be systematically varied, Figure 9. Peak plasmon resonances of between 500 and 1200 $\mathrm{nm}$ may be obtained by control of the reaction parameters. ${ }^{129}$ 


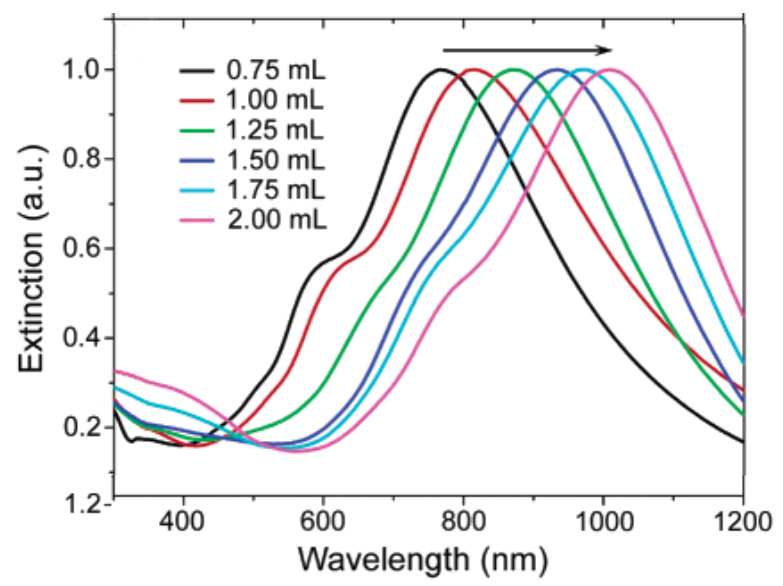

Figure 9. Tunable plasmon resonance of Au nano-cages. The arrow shows the effect of increasing additions of $\mathrm{HAuCl}_{4}$. (Reprinted with permission from ref ${ }^{129}$. Copyright 2008 American Chemical Society.)

The widely-used seeded wet chemical process to produce gold nanorods includes the co-addition of a small amount of $\mathrm{AgNO}_{3}$ to control the aspect ratio of the rods, ${ }^{133}$ a discovery that follows on from the apparently serendipitous observation by Chang et al. in 1999 that, when a silver electrode was used in the (quite different) electrolysis process to make Au nanorods, ${ }^{134}$ improved shape control was obtained. It is but a small step from there to use a two-stage synthesis technique to overcoat Au nanorods with Ag, ${ }^{101}$ 101,135-145 something apparently first achieved in $2001^{101}$ and investigated several times since. $^{101,135-145}$ Alternatively, Ag can be induced to grow on the ends of the Au rod cores to make a segmented hybrid.

The optical properties of the resulting hybrid nanorods depend on the aspect ratio, shape, and distribution of the Ag, and are very tunable. While the longitudinal extinction peak of the underlying nanorod core can be extended deep into the near-infrared by control of its aspect ratio, ${ }^{7}$ it is blue-shifted when coated with Ag. This is a combined effect due to both a decrease in aspect ratio due to the additional material and the introduction of the Ag with its different dielectric properties. The onset of a new peak, at a similar position to that of a nanosphere of $\mathrm{Ag}$, has also been observed. ${ }^{101,135-137,142,145}$ The results have been qualitatively reproduced by modeling, ${ }^{136,142,145-146}$ Figure 10 . In contrast, selective growth of Ag on the ends of the Au nanorods (to make a dumbbell for example) causes a small red shift 
in the longitudinal resonance, an effect that can be discerned in some experimental data and simulations. ${ }^{144,146-148}$ If the $\mathrm{Ag}$ shell is not cylindrical and is instead a parallelepiped, ${ }^{123}$ then there will be more than one new peak from the Ag shell due to loss of rotational symmetry.

The inverse geometry, in which $\mathrm{Au}$ is deposited onto an $\mathrm{Ag}$ nanorod core has been less studied, probably because Ag nanorods cores are more difficult to make. In addition, in this case galvanic displacement of the Ag nanorod core by Au is a likely outcome, a factor that has been recently exploited to make an elongated hollow capsule. ${ }^{149}$ Trimetallic nanorods, with an Au core, and shells of Ag and Hg, have also been prepared. ${ }^{150}$ The Hg coating caused a strong blue shift of the longitudinal plasmon resonance of the rod.

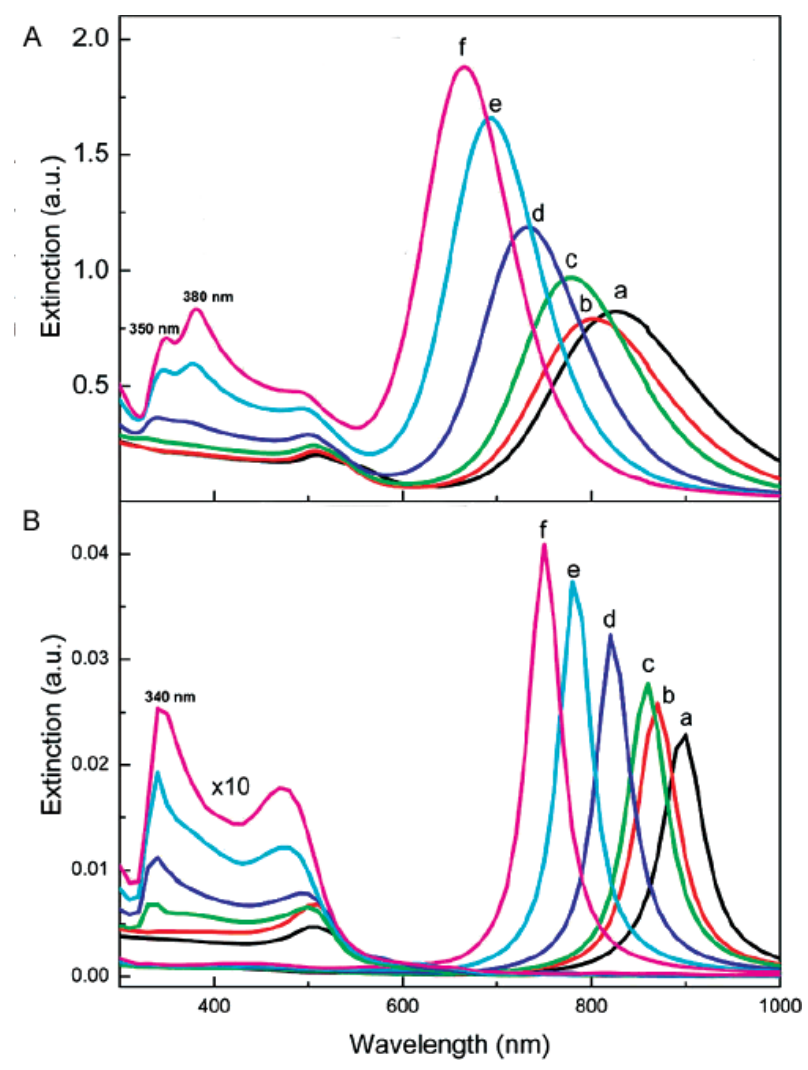

Figure 10. A typical example showing the effect of an $\mathrm{Ag}$ overcoat on the extinction spectrum of $\mathrm{Au}$ nanorods. As more Ag is deposited, the longitudinal plasmon resonance of the rod blue-shifted and intensified, while new peaks due to the $\mathrm{Ag}$ appeared at about 350 and $380 \mathrm{~nm}$. (a) experimental results, (b) calculated for these particles morphologies. (Reprinted with permission from ref ${ }^{145}$. Copyright 2008 American Chemical Society.) 
In general, the measured resonance peaks of the individual hybrid nanoparticles are broadened considerably by the addition of an $\mathrm{Ag}$ shell, which has been attributed to damping at the $\mathrm{Au} / \mathrm{Ag}$ interface. ${ }^{136}$ However, when considered at an ensemble level, the average line widths of distributions of Ag-coated nanorods might actually decrease, Figure 11, an effect investigated by Sönnichsen et al. and described by them as 'plasmonic focusing' ${ }^{137}$ A given thickness of Ag-coating has a greater blueshifting effect on the plasmon resonance of longer nanorods than on shorter ones, leading to their resonance peaks to 'bunch' up in the ensemble as the Ag shell is formed. Finally, there has been some interest in the non-linear optical properties of these the hybrid nanorods and the non-linear refractive index of Ag-coated Au core nanorods is reported to be enhanced by a factor of $8 .{ }^{151}$

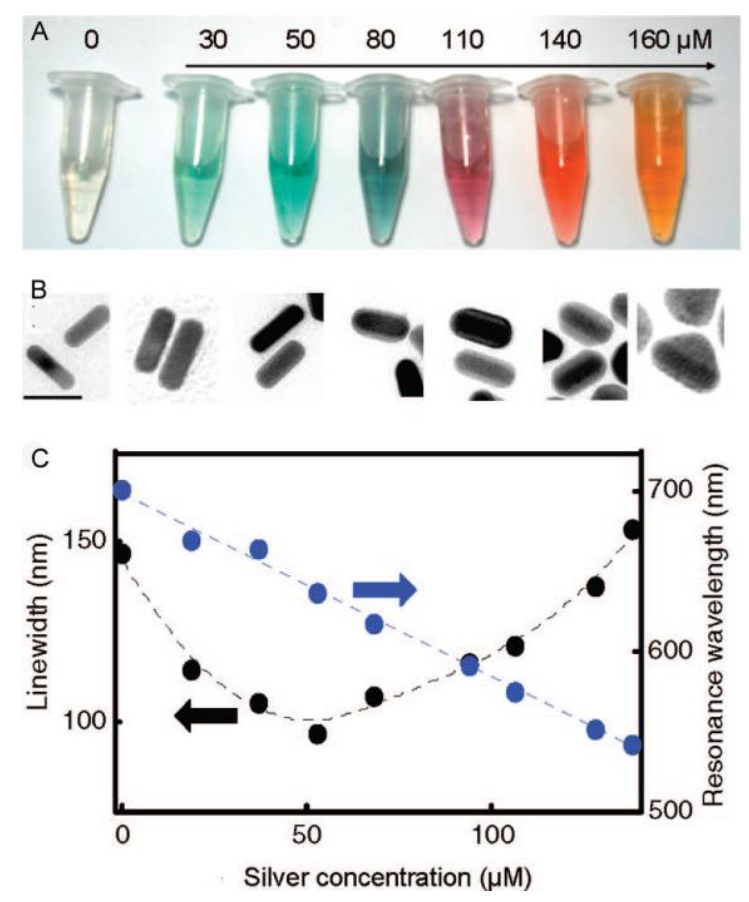

Figure 11. The blue-shifting effect of an Ag shell is relatively greater for rods of longer aspect ratios and so the line width of the ensemble's longitudinal plasmon resonance peak can be initially decreased by addition of Ag. (a) Samples of colloid showing variation in color, (b) TEM images of corresponding Au@Ag core-shell nanorods. The Ag content of the samples in (a) and (b) increases from left to right as shown. (c) Variation of line width of the ensembles' plasmon resonances and resonance wavelength, as a function of $\mathrm{Ag}$ addition. (Reprinted with permission from ref $^{137}$. Copyright 2008 American Chemical Society.) 
It is also possible to overcoat $\mathrm{Ag}$ onto core shapes other than spheres or rods. Nano-triangles, nanopods or octohedra can be coated with $\mathrm{Ag}^{152-155}$ in the same way. For example, Tsuji et al. ${ }^{122}$ recently overcoated gold icosahedra with $\mathrm{Ag}$ and studied the range of morphologies that resulted. The resulting samples had extinction spectra with peaks corresponding to both $\mathrm{Ag}$ and $\mathrm{Au}$, but these peaks were much broader than the peaks of pure nanospheres of the elements would have been. In contrast, narrower extinction peaks were obtained for Ag-coated Au nano-triangles and these could be readily tuned between 800 and $1300 \mathrm{~nm}^{153}$ by control of the Ag content of the solution; more Ag produced a blue shift. The blue shift was ascribed to the thickening of the nano-triangles with increased Ag (and hence a geometric effect), rather than being due to the differing dielectric properties of the Ag shell, ${ }^{153}$ but it seems probable that the strong masking effect that metallic overcoats have on any resonance of the underlying core should have also played a role. The shape of the overgrown Ag nanocrystal can be controlled by use of surfactants or by controlling the reaction conditions. Thus Au nanotriangle cores can also be buried in cubes, triangular prisms or other shapes of Ag. ${ }^{152}$

In summary, the creation of $\mathrm{Ag} / \mathrm{Au}$ core-shells and composite nanorods particles allows plasmon resonances to be tuned across the visible spectrum, ranging from the $380 \mathrm{~nm}$ of an $\mathrm{Ag}$ nanosphere to the near-infrared of $\mathrm{Au}$ nanorods and nanotriangles. Control of the degree of alloying vs. chemical segregation, aspect ratio, and the location of shell deposition (flanks vs. ends) provides flexibility. The significant enhancement of the Au resonance that results from the deposition of very modest Ag shells is worthy of further exploration as it is potentially useful in technological applications.

\section{$\underline{3.1 .1 .2 \mathrm{Au} / \mathrm{Cu}}$}

$\mathrm{Au} / \mathrm{Cu}$ nanoparticles have been studied intermittently for some years ${ }^{87,156}$ and there has been particular interest in theoretical simulations of their cluster geometry and properties. ${ }^{11}$ As for $\mathrm{Au} / \mathrm{Ag}$, the plasmon resonances of the alloy particles can be interpolated between those of $\mathrm{Au}$ and those of $\mathrm{Cu}$ by 
varying the stoichiometry of the particle..$^{95-96,106,157}$ The plasmon resonance of $\mathrm{Cu}$ is relatively weak however, so the effect of the inclusion of $\mathrm{Cu}$ in nanospheres is mainly to attenuate the resonance peak of the $\mathrm{Au}$ (see, for example refs. ${ }^{106,158}$ ). The physical metallurgy of the $\mathrm{Au}-\mathrm{Cu}$ system at temperatures below $410^{\circ} \mathrm{C}$ is relatively complex, with a series of ordered superlattices corresponding to $\mathrm{AuCu}_{3}$, $\mathrm{AuCu}-\mathrm{I}, \mathrm{AuCu}-\mathrm{II}$ and $\mathrm{Au}_{3} \mathrm{Cu}$ forming in bulk samples, given sufficient time, ${ }^{83}$ while at temperatures above $410^{\circ} \mathrm{C}$ the two elements form a solid solution at all stoichiometries. Is the lattice of the reported $\mathrm{Au} / \mathrm{Cu}$ nanoparticles ordered or random? Contradictory or ambiguous results have been reported $^{11,87,91,96,106}$ but the result is of more than academic interest since the optical properties of the ordered and disordered forms diverge strongly in the Drude regime of intraband transitions. For example, for the $\mathrm{AuCu}$ stoichiometry the values of $\varepsilon_{1}$ for the two phases are comparable, ${ }^{97}$ but $\varepsilon_{2}$ for the disordered phase become significantly larger than that of the ordered phase as wavelength is increased beyond $680 \mathrm{~nm},{ }^{159}$ Figure 12. Therefore, it might be expected that the resonance in an anisotropic nanoparticle of ordered phase would be stronger and sharper, ${ }^{97}$ with the difference becoming more marked as the plasmon resonance is displaced towards longer wavelengths as, for example, by increasing the aspect ratio of the nanoparticle. It is also the case that ordered $\mathrm{AuCu}$ has a lower DC electrical resistivity than the disordered phase, ${ }^{160}$ a factor which is in principle correlated with a reduction in intraband damping in Drude metals ${ }^{97}$. 


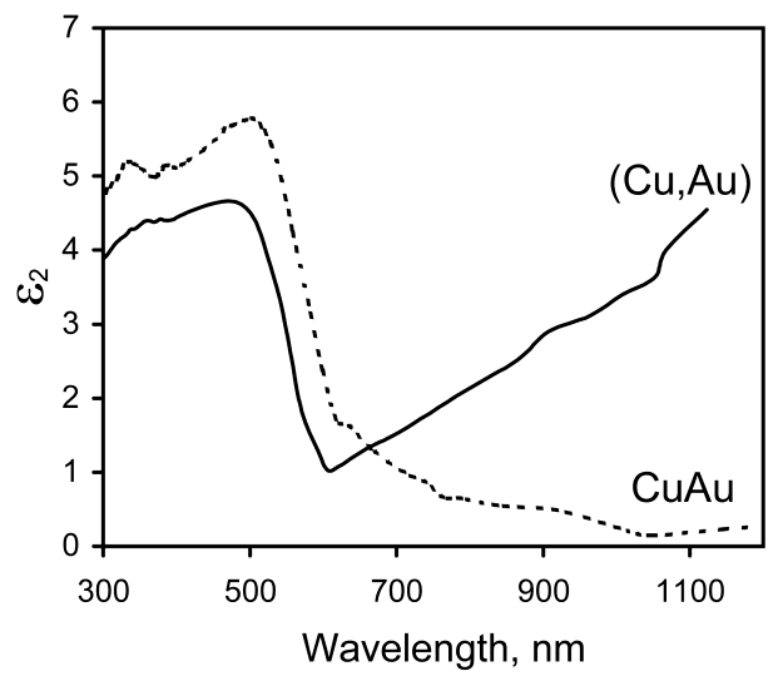

Figure 12. Approximate values of the imaginary part $\left(\varepsilon_{2}\right)$ of the dielectric permittivity of $\mathrm{CuAu}$ intermetallic compound compared to that of the equivalent disordered, equiatomic $\mathrm{Cu}, \mathrm{Au}$ alloy. Redrawn from data in ref. ${ }^{159}$ and rescaled here to units of wavelength (minor peaks and spectral features in the original data have been smoothed out in this representation).

Core-shell nanoparticles of $\mathrm{Au}$ and $\mathrm{Cu}$ have also been prepared. Co-impregnation of silica with $\mathrm{Cu}\left(\mathrm{NO}_{3}\right)_{2}$ and $\mathrm{HAuCl}_{4}$ followed by reduction was investigated for catalysis applications ${ }^{70}$ whereas colloidal Au@Cu structures have been made by sequential reduction. ${ }^{156}$ Interestingly, it was reported in 1984 that the $\mathrm{Au}$ in $\mathrm{Au} / \mathrm{Cu}$ particles segregates to the core in reducing conditions and to the surface under oxidizing conditions. ${ }^{161}$ In principle, this should give a plasmon resonance wavelength that is modulated by the partial pressure of oxygen but the idea seems not to have been explored further.

Alloyed nanorods of $\mathrm{Au}$ and $\mathrm{Cu}$ were found to be random solid solutions as-synthesized, but they ordered to the $\mathrm{AuCu}$ intermetallic phase when heated to $400^{\circ} \mathrm{C}$ in a $\mathrm{TEM}^{97}$ The line widths of the resonances were determined from scattering off individual particles and varied as the stoichiometry of the particle was changed with the minimum line width observed for a $\mathrm{Au}: \mathrm{Cu}$ ratio of 1:1. It was suggested that an ordered phase had formed from the heat of the illuminating light source in the experiment. This is feasible as $\mathrm{Au} / \mathrm{Cu}$ alloys order quite rapidly once heated above about $100^{\circ} \mathrm{C}$. Earlier 
work $^{159}$ suggests that $\varepsilon_{2}$ is greater for the disordered phase than for the ordered phase (thereby suggesting a stronger plasmon resonance for the latter) although the contrary has also been reported. ${ }^{97}$

It is interesting to note that ordered intermetallic $\mathrm{AuCu}$ nanoparticles can be converted to $\mathrm{AuCu}_{3}$ by heating at $315^{\circ} \mathrm{C}$ in a tetraethylene glycol solution of $\mathrm{Cu}\left(\mathrm{C}_{2} \mathrm{H}_{3} \mathrm{O}_{2}\right)_{2} \cdot \mathrm{H}_{2} \mathrm{O} .{ }^{162}$ The very high surface to volume ratio of the nanoparticles evidently imparts quite high chemical reactivity. This may prove in the future to be another strategy to control composition, and hence the wavelength of the plasmon resonance.

There has been some interest in the non-linear optical properties of hybrid $\mathrm{Au} / \mathrm{Cu}$ nanoparticles, however, the best figures-of-merit obtained so far, while promising, still fall short of the requirements of all-optical switching devices. ${ }^{96}$

\subsubsection{3 $\mathrm{Cu}-\mathrm{Ag}$}

At room temperature, bulk $\mathrm{Cu}$ and $\mathrm{Ag}$ have negligible solubility for one another ${ }^{83}$ (although nanoparticles of less than about 270 atoms $(\sim 1 \mathrm{~nm})$ would be expected to be alloyed on the basis of the surface energy argument and simulations mentioned above ${ }^{89}$ ). Therefore, $\mathrm{Cu}$ and $\mathrm{Ag}$ are promising materials for constructing core-shell hybrids with diameters in the typical colloidal range (5 to $50 \mathrm{~nm}$ for metallic particles). However, there are comparatively few studies of this system. An early study of sub$10 \mathrm{~nm}$ nanoparticles prepared by co-impregnation of the $\mathrm{Cu}$ and $\mathrm{Ag}$ nitrates into a porous silica support followed by calcination showed that the $\mathrm{Cu}$ tended to migrate to the core and the Ag to the surface. ${ }^{161}$ $\mathrm{Ag}$ and $\mathrm{Cu}$ can also be loaded into bulk glass or silica by ion implantation or by ion exchange from a molten salt, and it has been claimed that both $\mathrm{Ag} @ \mathrm{Cu}$ and $\mathrm{Cu} @ \mathrm{Ag}$ particles of less than about 10 nm can result from these processes, depending on sequence of treatments. ${ }^{163-164}$ The optical properties of the Ag@Cu particles in both cases are similar to those of an Ag nanosphere, with only a small shoulder at $550 \mathrm{~nm}$ from the $\mathrm{Cu}$. It was suggested that the shape of the optical absorption spectrum was evidence for core-shell particle formation ${ }^{163-164}$ but it could be argued that two separate populations of 
nanoparticles were formed, or that the $\mathrm{Cu}$ shell had partially oxidized. In contrast, $\mathrm{Cu} @ \mathrm{Ag}$ particles prepared by Manikandan et al. ${ }^{163}$ exhibited a single, rather broad, resonance at about $440 \mathrm{~nm}$, as expected from a damped $\mathrm{Cu}$ core plasmon resonance and a strong Ag shell resonance.

Core-shell particles of the $\mathrm{Cu} @ \mathrm{Ag}$ type have also been prepared by physical vapor deposition ${ }^{165}$ or sonochemistry followed by galvanic displacement, ${ }^{63}$ and of the $\mathrm{Cu} @ \mathrm{Ag}$ and $\mathrm{Ag} @ \mathrm{Cu}$ types by reduction in ethylene glycol. ${ }^{166-167}$ The polyol technique of Tsuji et al. is quite useful for this system and, besides the core-shells mentioned, can also produce alloy particles ${ }^{168}$ and heterodimers, ${ }^{169}$ Figure 13. Presumably, however, the alloy particle is metastable and might demix readily if heated.

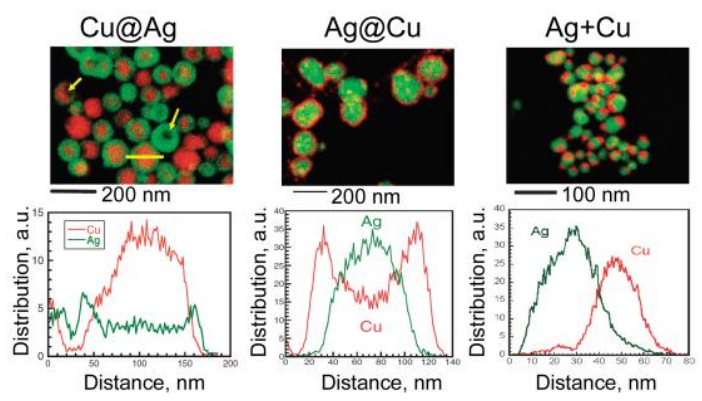

Figure 13. Three morphologies of $\mathrm{Cu} / \mathrm{Ag}$ hybrid nanoparticles, prepared by reduction in ethylene glycol, with product type controlled by the reaction parameters. Reproduced from refs. ${ }^{166-167,169}$ with permission of The Chemical Society of Japan.

In the case of the particles prepared by physical vapor deposition, the structure of the $\mathrm{Cu} @ \mathrm{Ag}$ depends on the particle diameter; $\mathrm{Cu} @ \mathrm{Ag}$ core shell particles formed only when the overall diameter was $<12 \mathrm{~nm}^{165}$ In general it appears that simple two-phase heterostructures are more stable above that size. ${ }^{63,165,170}$ The transition in morphology may be due to a mismatch in lattice parameter, such that an epitaxial Ag shell is not favored above $12 \mathrm{~nm}$ diameter. ${ }^{165}$ Hybrid nanoparticles of about five nanometers diameter have also been produced by spark discharge and were found to be two-phase. ${ }^{171}$

\subsubsection{Cu-Ag-Au}

Three-way hybrids of the coinage metals are also possible. Strictly speaking, the nanoparticles in the 
famous Roman Lycurgus Cup are $\mathrm{Cu}-\mathrm{Ag}-\mathrm{Au}$ hybrids, with a composition of about 60\% $\mathrm{Ag}, 30 \% \mathrm{Au}$ and $10 \% \mathrm{Cu} .{ }^{99}$ There are only a few examples of studies into hybrids of these three elements though. Chatterjee $^{91}$ prepared $\mathrm{Au}-\mathrm{Ag}-\mathrm{Cu}$ nanoparticles of 20 to $50 \mathrm{~nm}$ diameter by simultaneous physical deposition of the elements. The resulting hybrid was not single phase and partitioned into one or more coherent domains of Ag-rich face-centered cubic phase and ordered $\mathrm{AuCu}_{3}$. Later, Pal et al. reported that they had successfully prepared true alloy hybrid nanoparticles of these three elements within a $\mathrm{SiO}_{2}$ matrix, a conclusion based on the presence of a single plasmon resonance peak at $480 \mathrm{~nm}$ and the results of electron dispersive spectroscopy analyses ${ }^{172}$. Onion-like core-shell particles, consisting of an $\mathrm{Au}$ core, and then successive shells of $\mathrm{Ag}$ and $\mathrm{Cu}$ were reported by Belloni et al. ${ }^{115}$

\subsubsection{Hybrids with platinum group metals}

Some early experiences of the optical properties of coinage metal/platinum group metal hybrids were summarized by Belloni ${ }^{173}$ and illustrated some important principles. In particular, the plasmon resonance of a coinage metal core is very rapidly damped by any platinum group metal shell, which somewhat mitigates against use of these structures in optical applications.

\section{$\underline{3.1 .2 .1 \mathrm{Au} / \mathrm{Pd}}$}

Au@Pd particles have been studied for some decades, primarily as catalysts, with their optical properties often utilized as tools for characterization. In the bulk phase, the two elements are mutually soluble at elevated temperatures but will over time form ordered compounds at lower temperatures, ${ }^{83}$ similar to the behavior of the $\mathrm{Cu}-\mathrm{Au}$ system. Particles produced by simultaneous reduction of $\mathrm{HAuCl}_{4}$ and $\mathrm{PdCl}_{2}$ using ethanol as the reductant ${ }^{174}$ were characterized using EXAFS, which indicated an Au core with an outer Pd-rich zone on the surface. ${ }^{174-175}$ The plasmon resonance of the Au was attenuated and eventually suppressed as the Pd:Au ratio was increased. Later work showed that annealing at 
temperatures up to $573 \mathrm{~K}$ homogenized the alloy to produce a random solid solution ${ }^{175}$ but the optical properties of this structure were not reported. Clearly, the initial presence of the Au core in this work is the result of the more noble nature of $\mathrm{Au}$, which was reduced first, rather than to any thermodynamic structural considerations peculiar to this size of nanoparticle and these elements. Curiously, if the reduction reactions are conducted sequentially, then quite different outcomes result depending on the order. Reduction of Au followed by Pd produced a mixed monometallic population of elemental nanoparticles, whereas the reaction of existing Pd nanoparticles with Au ions produced a hybrid dualphase nanoparticle in which, apparently, the surface contained a mixture of Au- or Pd-rich ${ }^{176}$ regions. Li et al. ${ }^{45}$ produced $\mathrm{Au} @ \mathrm{Pd}$ nanoparticles by thermal decomposition of $\mathrm{PdCl}_{2}$ on existing Au nanoparticle cores, and Wong et al. ${ }^{177}$ deposited Pd onto a colloid of Au nanoparticles. In both cases it was found that the plasmon resonance of the Au rapidly disappeared. It cannot be determined from this observation whether the attenuation of the Au resonance was due to the formation of a Pd shell, or a $\mathrm{Au}-\mathrm{Pd}$ alloy, as both scenarios would have similar effects. Incidentally, alloying with $\mathrm{Pd}$ or $\mathrm{Ni}$ is commonly used to bleach the yellow color of gold to make 'white gold' for jewelry ${ }^{178}$ - a macroscale demonstration of the strong effect that alloying has on the electronic structure of Au.

The precipitation of Pd onto Au nanorod cores has also been demonstrated ${ }^{135,179}$ and as expected, as the Pd shell thickened, the longitudinal and transverse resonances of the underlying rod were attenuated, Figure 14. Under appropriate conditions, very regular parallopipeds of Pd with a Au nanorod core can be synthesized. ${ }^{179}$ 


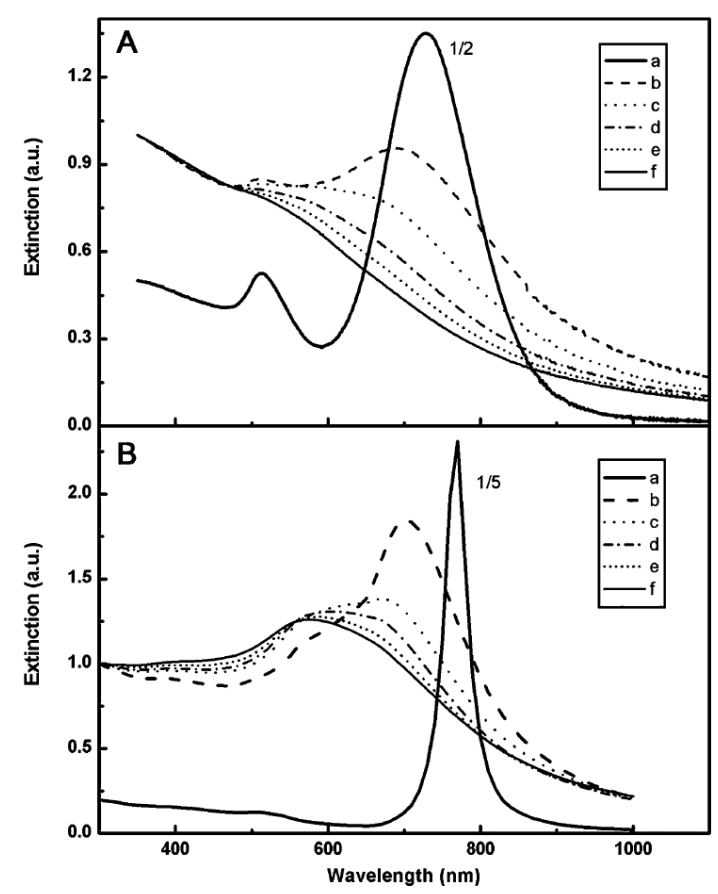

Figure 14. Rapid attenuation of the core resonance of a Au@Pd hybrid nanorod with increase in thickness of the Pd shell. Curves $a$ to $f$ representing increasing thickness of Pd. (a) measured data, (b) simulated effect. (Reprinted with permission from ref. ${ }^{179}$ Copyright 2006 American Chemical Society.)

The whimsically-named 'tadpole' nanoparticle consists of a spherical Au 'head' and a Pd nanorod 'tail', ${ }^{180}$ Figure 15. It was made by galvanic displacement of $\mathrm{Pd}$ by $\mathrm{Au}$, which under appropriate conditions occurs only on the ends of the Pd nanorods. Later, Ostwald ripening causes one of the two $\mathrm{Au}$ ends to grow at the expense of the other to produce the 'tadpole'. In these particles, there is a weakly-developed plasmon resonance in the vicinity of $560 \mathrm{~nm}$ due to the spherical gold 'heads'. 

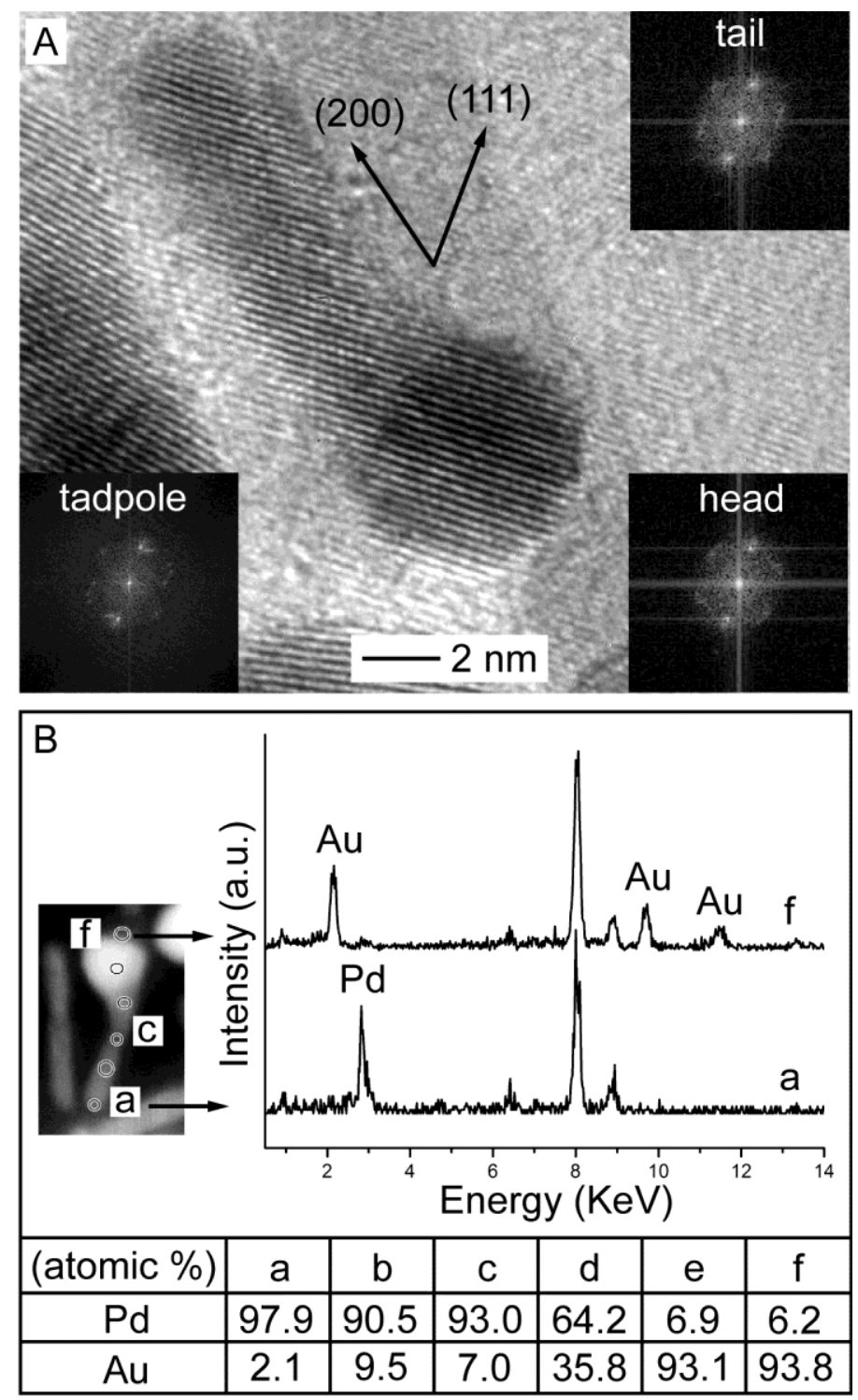

Figure 15. (a). Au nanospheres can be grown epitaxially on one end of a $\mathrm{Pd}$ nanorod to produce a shape that has been termed a 'tadpole'. (b). The composition of each part of the hybrid nanoparticle was confirmed by STEM/EDS. (Reprinted with permission from ref. ${ }^{180}$ Copyright 2007 American Chemical Society.)

\section{$\underline{3.1 .2 .2 A u / P t}$}

$\mathrm{Au}$ and Pt have limited mutual solubility in the bulk phase ${ }^{83}$ and alloyed nanoparticles of more than 3 to $6 \mathrm{~nm}^{84-85,171}$ are not readily produced. ${ }^{115}$ In the range of sizes that are associated with a welldeveloped plasmon resonance (usually 10 to 100 nm) it appears that only Au@Pt or Pt@Au core-shells 
have been made. If single phase particles are desired, as catalysts for example, then a very energetic reduction, such as by application of electron beam radiation, can suppress de-mixing ${ }^{181}$ but the particles produced will be only about $2 \mathrm{~nm}$ in diameter with no plasmon resonance in the visible or near-visible regime. $^{181}$

Many schemes to produce Au@Pt and Pt@Au core shell particles have been reported since the mid1990s. ${ }^{115}$ The overall diameter of such nanoparticles must be bigger than the threshold below which alloying occurs. In particular, due to the relatively lower surface energy of Au than Pt, a Pt@Au particle would be favored. ${ }^{85} \mathrm{An}$ Au shell on a Pt core has a plasmon resonance peak of about $520 \mathrm{~nm}$, if thick enough. ${ }^{64}$ Once again, the shell's plasmon resonance is similar to that of a solid nanosphere of the same composition, rather than the red-shifted resonance expected of a hollow or dielectric-cored Au structure. Similar to Au@Pd, the resonance in Au@Pt is attenuated with a reasonably thin shell of Pt. ${ }^{115,182}{ }^{183-185}$ Evidently, the highly damped plasmon response ${ }^{76}$ of the platinum group metal shields the gold core and attenuates its oscillation. An intriguing inversion of the core -shell geometry as a result of high intensity laser irradiation has been reported, in which a Au@Pt particle of 20 to $30 \mathrm{~nm}$ becomes changed into a Pt@Au one. ${ }^{186}$ The reorganization when the particle solidifies after the laser pulse is presumably a result of the lower surface energy of the Au relative to the Pt and its lower melting point.

Damping was also observed when Pt was deposited onto Au nanorods. If, however, the Pt is preferentially deposited on the ends of the rod, then the longitudinal resonance red-shifts, ${ }^{185}$ a phenomenon also observed for Ag deposition onto the ends of Au nanorods. A small degree of redshifting also occurred when a sparse, incomplete coverage of Pt nanospheres ${ }^{187}$ or Ag/Pt nanospheres ${ }^{188}$ was deposited onto a $\mathrm{Au}$ nanorod core. In these cases, the longitudinal plasmon resonance of the rod was only relatively modestly attenuated. This is because the Au core in these instances is not covered by a continuous later of metal, so its resonance is not suppressed and instead only red shifted by the increase in near-field dielectric permittivity.

FePt@Au particles have also been prepared and have a plasmon resonance at about 540 nm. ${ }^{189}$ As 
synthesized, the particles were superparamagnetic, but became ferromagnetic after annealing at $400^{\circ} \mathrm{C}$ ostensibly corresponding to a transition of the core from a disordered face centered cubic Fe,Pt solid solution to the ordered FePt phase.

Nanorods or nano-cylinders can be produced by electrodeposition within the pores of an alumina template. The process to produce single component nanorods this way dates from $1989,{ }^{190}$ while the idea of varying the electroplating solution to produce a free hybrid nanoparticle seems to have appeared in $1999,{ }^{54}$ in this case to produce an Au-Pt-Au nanocylinder of $200 \mathrm{~nm}$ diameter and considerable length. Autonomous propulsion of such objects by catalytic decomposition of $\mathrm{H}_{2} \mathrm{O}_{2}$ was realized in $2004,{ }^{191}$ and has been studied several times since, with some refinements such as the addition of a magnetic Ni component to provide another means of external control, ${ }^{192}$ the use of other platinum group metals as catalyst, ${ }^{55}$ or asymmetric deposition of the catalyst to give a rotary motion. ${ }^{193}$ However, these particles are too large to exhibit localized plasmon resonances and their optical properties are due to scattering of the incident light.

\subsubsection{Ag-platinum group metal}

Simultaneous radiolytic reduction of mixed $\mathrm{Ag}$ and Pd salts produced alloyed nanoparticles of $\mathrm{Ag}$ and $\mathrm{Pd}$, and the plasmon resonance could be tuned between that of $\mathrm{Ag}(\sim 400 \mathrm{~nm})$ and that of $\mathrm{Pd}(\sim 200 \mathrm{~nm})$ by control of the stoichiometry. ${ }^{115}$ A similar result can be obtained by rapid reduction of a solution of mixed precursors with hydrazine. ${ }^{194}$

Pd@Ag particles have a similar plasmon resonance wavelength (360 to $390 \mathrm{~nm}$ depending on shell thickness) ${ }^{195}$ to that of solid Ag nanospheres, in accordance with the general principle discussed earlier. Although $\mathrm{Ag}$ and $\mathrm{Pd}$ are mutually soluble at all stoichiometries ${ }^{83}$, this result strongly implies that these were true core-shell particles since a stronger blue shift in the peak position away from that of Ag would have been expected for alloy particles. However some alloying of $\mathrm{Ag}$ and $\mathrm{Pd}$ has been reported for ostensibly core-shell hybrids. $^{82}$ 
On the other hand, $\mathrm{Ag}$ and $\mathrm{Pt}$ have limited mutual solubility ${ }^{83}$ suggesting an intrinsic suitability for use in core-shell particles. Lee et al. attempted to prepare Ag@Pt and Pt@Ag nanoparticles by deposition-precipitation, but found that only the former could be successfully prepared under their conditions, with the reverse order of reactions creating separate populations of $\mathrm{Pt}$ and $\mathrm{Ag}$ nanoparticles. $^{92}$ The surface composition of their Ag@Pt was verified by a process of phase transfer from an aqueous phase into toluene, which would apparently occur only if the outer layers were Pt. A puzzling aspect of their work, however, was that their Pt-coated core shell particles retained the plasmon resonance of the $\mathrm{Ag}$ cores, which is not the behavior expected for a continuous Pt shell. In contrast, Bunker et al. ${ }^{82}$ prepared small Pt@Ag particles by radiolysis and observed the expected plasmon resonance due to $\mathrm{Ag}$ at about $360 \mathrm{~nm}$.

Kim et al. prepared Ag@Pt nanoparticles by aqueous deposition-precipitation and then converted them to hollow Pt shells by a process involving intense laser irradiation at $1064 \mathrm{~nm} .{ }^{196}$ The heated Pt shells melted and expelled the Ag core. The structures, before and after irradiation, had relatively featureless optical absorption, as would be expected from the Pt shell.

In summary, overcoating a plasmon-active coinage metal with a platinum group metal has the effect of destroying the coinage metal's plasmon resonance, whereas in the converse case, the coinage metal coating has the optical properties of a solid coinage metal nanosphere. From the point-of-view of the technological exploitation of the optical properties specifically, neither of these outcomes is particularly attractive.

\subsubsection{Hybrids with magnetic metals}

A number of magnetic hybrid nanoparticle systems have been investigated ${ }^{197}$ but few descriptions of their optical properties have been forthcoming. Systems such as Au-CoPt ${ }_{3}{ }^{197-198} \mathrm{Ag} @ \mathrm{Co},{ }^{199} \mathrm{FePt}-$ $\mathrm{Au},{ }^{198,200} \mathrm{FePt}-\mathrm{Ag},{ }^{201} \mathrm{Fe}_{3} \mathrm{O}_{4}-\mathrm{Au},{ }^{201}$ and $\mathrm{Fe} @ \mathrm{Au}^{202}$ prepared as core shell particles ${ }^{199,202}$ or as heterodimers ${ }^{197-198,200-201}$ would be expected to exhibit the plasmon resonance of their coinage metal 
component provided that it is not masked by a non-plasmonic shell. In some cases the shell resonance of the coinage metal, for example $\mathrm{Au}$ in the $\mathrm{Fe} @ \mathrm{Au}^{202}$ particles is a little red-shifted and attenuated compared to that expected from a solid $\mathrm{Au}$ nanosphere of similar diameter but such trends can be explained as the result of surface roughness, a red-shifting factor for nanoshells generally. ${ }^{203-204}$ In this respect, noble metal coatings might in some cases behave more like a hollow ensemble of loosely connected nanospheres than a true shell. ${ }^{205-207}$

In these systems, the magnetic properties and the optical properties are independent of one another. We will discuss the different and interesting concept of 'active' magnetic hybrids in Section 3.3.

\subsubsection{Au-Ni, $\mathrm{Au}-\mathrm{Fe}$ and $\mathrm{Au}-\mathrm{Co}$}

$\mathrm{Au}$ and $\mathrm{Ni}$ are almost completely immiscible in the bulk phase and so are good choices for the preparation of core-shells or other two-phase hybrid nanoparticles. Due to the lower surface energy of

Au relative to $\mathrm{Ni}^{127}$ the expected stable structure is $\mathrm{Ni@Au,} \mathrm{and} \mathrm{experimental} \mathrm{data} \mathrm{support} \mathrm{this.}{ }^{208-209}$ An increased proportion or coverage of $\mathrm{Au}$ provides an increasingly stronger plasmon resonance at about $520 \mathrm{~nm}$. Ni can be deposited onto Au nanorods, which can then be aligned in an external electric field. ${ }^{210}$ Controlled alignment of Au nanorods is an attractive outcome because it could provide a useful color change system, ${ }^{76}$ but coating the rods with Ni significantly attenuated the longitudinal plasmon of Au nanorods, Figure 16. Retention of the resonance of an Au core should possible in principle, however, provided that the thickness of the Ni is strictly limited. For example, Sánchez-Iglesias et al. have shown that the plasmon resonance of an Au nanosphere was still evident after it had been overcoated with up to $8 \mathrm{~nm}$ of $\mathrm{Ni}$ and $\mathrm{NiO} .^{211}$ 


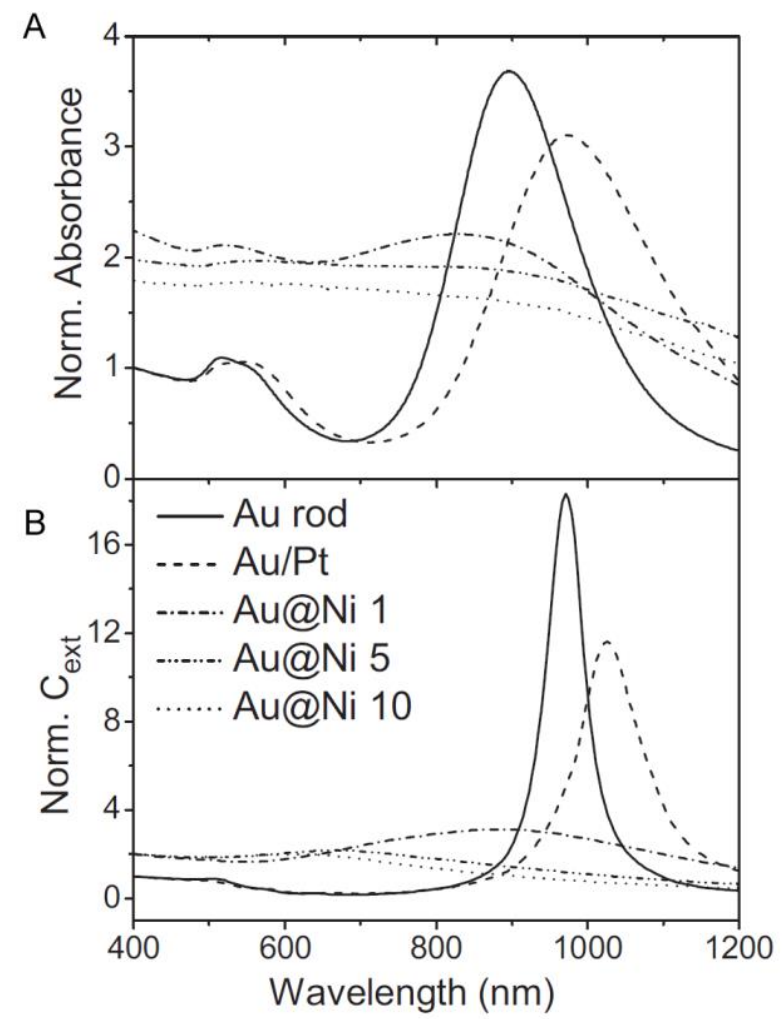

Figure 16. Overcoating Au nanorods with $\mathrm{Pt}$ and Ni results in complete attenuation of the longitudinal and transverse plasmon resonances. (a) Experimental data, (b) calculated for similar shapes. Copyright Wiley-VCH Verlag GmbH \& Co. KGaA. Reproduced from ref. ${ }^{210}$ with permission.

Although the bulk Au-Fe system exhibits similar immiscibility to bulk Au-Ni, alloyed nanoparticles of $\mathrm{Au}$ and $\mathrm{Fe}$ in the 4 to $6 \mathrm{~nm}$ size range have been prepared by ion implantation into a $\mathrm{SiO}_{2}$ matrix. $^{86}$ The plasmon resonance of the alloy is, however, rapidly attenuated by the additions of Fe.

Au-Ni hybrid nanorods can act as nanoscale rotors when tethered to a substrate by one end. ${ }^{212}$ The hybrid particles in this case were produced by electroplating into a porous $\mathrm{Al}_{2} \mathrm{O}_{3}$ template of about 200 nm diameter followed by release. Their movement could be observed in an optical microscope due to their scattered light.

Besides the core-shell and heterodimer morphologies mentioned above, it is also possible, under carefully controlled conditions, to precipitate gold nanospheres onto the ends or flanks of Co 
nanorods. $^{213}$ The site of nucleation of the Au nanospheres on the Co nanorod could be controlled by reaction parameters. Electron microscopy revealed that the $\mathrm{Au} / \mathrm{Co}$ interface of this hybrid was of the coherent type, with a (111) plane of Au matching up with a (002) plane of the Co.

\section{$\underline{3.1 .3 .2 \mathrm{Ag}-\mathrm{Ni}}$}

$\mathrm{Ni}$ and Ag are also expected to form core-shell particles of the Ni@Ag type, because these elements are completely immiscible as solid bulk materials, and because the surface energy of Ag is only about half that of $\mathrm{Ni}^{11}$ A similar tendency holds for Co and Ag. A study in which 2 to $5 \mathrm{~nm}$ particles containing these elements were prepared within a $\mathrm{Al}_{2} \mathrm{O}_{3}$ matrix found that the optical properties of both Ni@Ag and Co@Ag were dominated by the plasmon resonance of an Ag shell, which occurred, depending on thickness, between about 410 and about $450 \mathrm{~nm},{ }^{208}$ suggesting that core-shell particles had formed. In contrast, $\mathrm{Ag} / \mathrm{Ni}$ nanoparticles of about $8 \mathrm{~nm}$ diameter prepared by others were found to be homogenously alloyed. ${ }^{214}$ Evidently, the method of synthesis and thermal history of these types of particles has a large effect on their structure.

\subsubsection{Other metallic hybrids}

\subsubsection{Intermetallic compounds of the alkali metals}

Blaber et al. ${ }^{10,215}$ assessed a range of other intermetallic compounds and identified the coinage metal $\mathrm{CsCl}$ (B2) structured intermetallic compounds with the alkali metals, such as AuK, as candidates for plasmonic applications. Little experimental work has been performed to date on these systems, ${ }^{216}$ and the physical properties of AuK are somewhat uncertain. ${ }^{217}$ Hybrid nanoparticles in the sub-nanometer size range of $\mathrm{Na}$ or $\mathrm{Cs}$ with $\mathrm{Au}, \mathrm{Cu}$ or $\mathrm{Ag}$ have been prepared by a gas phase process but the optical properties have not been reported. $\mathrm{Au}_{2} \mathrm{Na}$ has been reported to have a bright brassy color in the bulk form $^{218}$ and so investigations into the optical properties of nanoparticles of this material may be warranted. 


\subsubsection{Other intermetallic nanoparticles}

There are other intermetallic compounds of coinage metals that are quite strongly colored, suggesting interesting dielectric functions in the visible range. The compound $\mathrm{AuAl}_{2}$, for example, is purple in the bulk phase. Due to the peculiar variation of its dielectric properties with wavelength, it has been predicted that nanoparticles would show dual broad plasmon resonances at both 480 and $600 \mathrm{~nm}$, Figure 17. ${ }^{219} \mathrm{AuAl}_{2}$ may be challenging to prepare in nanoparticle form by chemical methods (due to the reactivity of the $\mathrm{Al}$ ) but it is interesting to note that the isostructural $\mathrm{AuIn}_{2}$, which has a blue color ${ }^{220}$, has been prepared in nanoparticle form by physical vapor deposition. ${ }^{221} \mathrm{PtAl}_{2}$ has the same crystal structure as $\mathrm{AuAl}_{2}$ and $\mathrm{AuIn}_{2}$ but is bright yellow. ${ }^{222}$

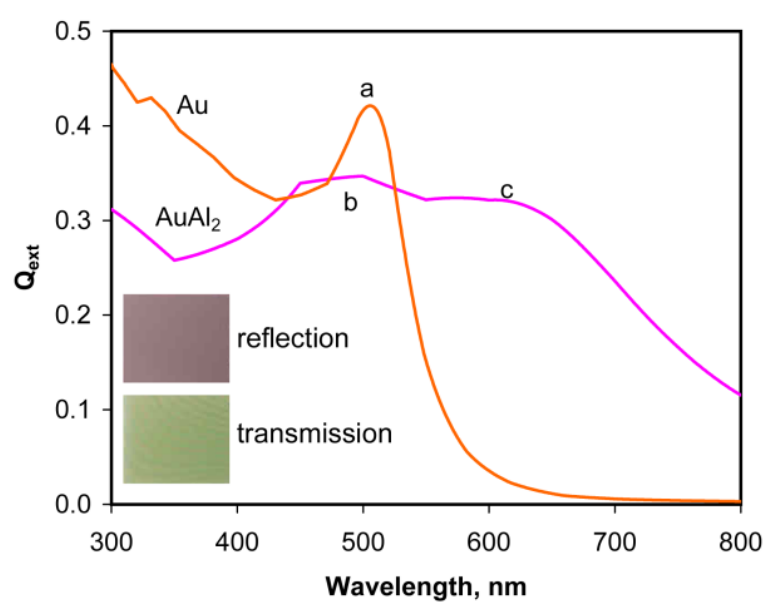

Figure 17. Some calculations suggest that nanospheres of $\mathrm{AuAl}_{2}$ should display two, overlapping, plasmon resonances $b$ and $c$. The simulation is for $20 \mathrm{~nm}$ diameter particles, with the resonance of a similarly sized Au nanosphere shown for comparison as $a$. Inset. Thin films of the intermetallic compound $\mathrm{AuAl}_{2}$ have a purple color in reflection and a green color in transmission. Redrawn from Supansomboon ${ }^{219}$ and reproduced with permission of Gold Bulletin.

$\mathrm{Cu}-\mathrm{Zn}$ nanoparticles ("nanobrass") of various stoichiometries and in the 5 to $10 \mathrm{~nm}$ size range have been prepared and their plasmon resonances are red-shifted and rapidly attenuated from that of $\mathrm{Cu}$ as the proportion of $\mathrm{Zn}$ is increased. Surprisingly, these particles consisted of more than one phase (there are 
several possibilities in the $\mathrm{Cu}-\mathrm{Zn}$ binary phase diagram) despite their small size. ${ }^{223}$ In general, the core seems enriched in $\mathrm{Cu}$ in these structures. ${ }^{11}$ AuZn would be another prospective basis for a plasmon resonance in the visible range of the spectrum. ${ }^{10}$

In addition to the various systems already mentioned, $\mathrm{Ag} @ \mathrm{Cd},{ }^{224} \mathrm{Ag} @ \mathrm{~Pb},{ }^{105} \mathrm{Au} @ \mathrm{Sn},{ }^{225}$ and even $\mathrm{Au} @ \mathrm{~Pb} @ \mathrm{Cd}^{226}$ may be added. More recently, Fe@Au, Fe@Pt, Fe@Pd have also been synthesized, but the optical properties were unremarkable, with only the slightest of plasmon resonance peaks evident for the Au-coated samples. ${ }^{227} \mathrm{Se} @ \mathrm{Au}$ and Se@Ag have been synthesized, ${ }^{228}$ and the optical absorption spectra of both are dominated by the shell, and similar to a solid nanosphere of the shell composition. A novel approach to the synthesis of a metal-dielectric hybrid was to prepare bimetallic AuCd nanoparticles first, and then react them at $250^{\circ} \mathrm{C}$ with a solution containing Se to finally produce Au@CdSe core-shells. ${ }^{229}$ The plasmon resonance of the core was retained in the hybrid, albeit red shifted by about 10 to $15 \mathrm{~nm}$, since the CdSe is non-metallic and does not screen the core. A similar effect holds when coating an $\mathrm{Au}$ core with $\mathrm{SnO}_{2}$ (rather than $\mathrm{Sn}$ ). ${ }^{230}$

Hybrids of the coinage metals and some other non-magnetic, non-platinum group element might be useful for several reasons. A core of an active metal such as Co can serve as a sacrificial template to prepare hollow gold nanoshells, and although the amount of red-shifting (the main technological motivation for doing this) initially obtained was initially relatively modest, ${ }^{231}$ further refinements to the process have demonstrated hollow gold nanoshells with strong plasmon resonance peaks that can be tuned from 520 to $850 \mathrm{~nm} \cdot{ }^{232}$ Alternatively, hybrid nanoparticle semi-shells of concentric layers of $\mathrm{Au}$, $\mathrm{Al}$ and $\mathrm{Au}$ have been prepared by physical vapor deposition onto a nanosphere template, and dissolution of the $\mathrm{Al}$ in an alkali produces a 'nanobell', in principle with an ostensibly detached core. ${ }^{233}$ Similarly, dissolution of $\mathrm{Fe}_{3} \mathrm{O}_{4}$ in $\mathrm{Au} / \mathrm{Si} / \mathrm{Fe}_{3} \mathrm{O}_{4}$ hybrids has been shown to produce 'nanorattles', consisting of a hollow silica shell containing a small number of Au nanospheres ${ }^{234}$.

The general principle that the optical properties of the hybrid closely resemble those of the shell material also holds for these examples. ${ }^{226}$ 


\subsection{Passive metallo-dielectric hybrids}

This section discusses hybrid metallo-dielectric nanoparticles in which the two or more components have independent functionalities that do not interact significantly, at least in so far as the optical properties are concerned.

There are many reports of coinage metal / semi-conductor hybrids in the category of 'passive' metallic-dielectric hybrids. $\mathrm{CdS} / \mathrm{Au}, \mathrm{PbS} / \mathrm{Au}$ and $\mathrm{PbS} / \mathrm{Ag}, \mathrm{Fe}_{3} \mathrm{O}_{4} / \mathrm{Ni}$ and $\mathrm{Fe}_{3} \mathrm{O}_{4}-\mathrm{Pt}, \mathrm{Au} / \mathrm{MnO}$ and $\mathrm{Au} / \mathrm{Fe}_{3} \mathrm{O}_{4}$ are but a few of the many possibilities that have been reported. ${ }^{25,235-238}$ Core-shells, heterodimers, and even more complex shapes have been prepared. A general review of passive hybrid nanoparticles made by the precipitation of noble metals onto diverse semi-conductors, and vice versa, was recently provided by Costi et al., ${ }^{25}$ while Zeng et al. ${ }^{29}$ have recently reviewed passive hybrid nanoparticles in which one component is a magnetic material.

In the case of coinage metal@dielectric hybrids, or coinage metal/dielectric heterodimers, the net effect on optical properties is often simply additive, with some red-shifting of the plasmon resonance due to a localized increase in the surrounding refractive index, ${ }^{25,29,31,44,230,239-243}$ Figure 18. However, red-shifting of the plasmon resonance obtained in this manner is generally less dramatic than the far more potent red-shift achievable by increasing the aspect ratio of the underlying coinage metal ellipsoid, nanorod or nanoshell.

In contrast, the dielectric@coinage metal geometry should, as described earlier, have the optical properties of a true metal shell for the most part, modified somewhat by the refractive index of the core. ${ }^{205}$ In this case, the resonance of the metal shell can be red-shifted significantly by reduction of its thickness, ${ }^{125}$ which provides a versatile platform for a variety of budding technological applications. ${ }^{244-}$ ${ }^{249}$ Alternatively, in the specific case of an Au shell, the resonance can be tuned to higher energies by overcoating with $\mathrm{Ag} .{ }^{250}$ A magnetic core can provide other useful features, such as the capability to move particles around by an external magnetic field. ${ }^{251}$ 


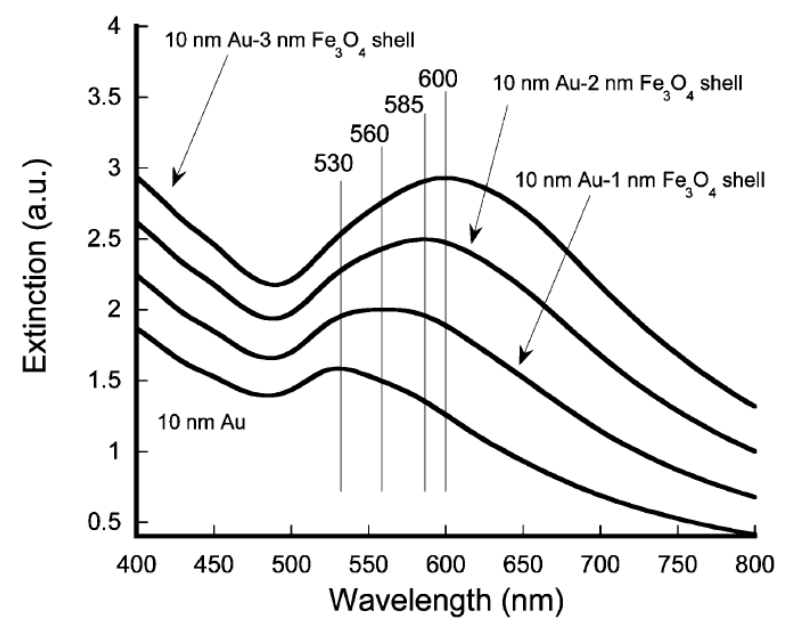

Figure 18. Red shift of underlying Au nanosphere due to increasing thickness of an $\mathrm{Fe}_{3} \mathrm{O}_{4}$ shell due to effect of local dielectric environment on the Au plasmon resonance. (Reprinted with permission from ref. ${ }^{240}$ Copyright 2006 American Chemical Society.)

An optically-related reason for coating noble metal nanoparticles with dielectric material is to prevent aggregation of the particles and hence collapse of their single-particle plasmon resonances. On the other hand, controlled aggregation, using a defined thickness of dielectric coating, may be useful at times as a means of developing a controlled interparticle plasmon resonance. This has considerable utility, since if $\mathrm{Au}$ or Ag nanoparticles, for example, are deliberately closely spaced (with an interparticle distance between about $1 \mathrm{~nm}$ and one particle diameter), there will be additional dipole-dipole plasmon resonances between adjacent particles which are strongly red-shifted relative to the single particle resonance. ${ }^{19,78}$ The effect can be exploited to make sensitive colorimetric biosensors to detect lead ions, cocaine, DNA or pregnancy, ${ }^{252-255}$ to name only a few of the possibilities. Coatings comprised of closely packed $\mathrm{Au}$ or $\mathrm{Au} @ \mathrm{SiO}_{2}$ particles, for example, exhibit a range of interesting and tunable optical properties due to this effect. ${ }^{256-257}$

In addition to spherical geometries, $\mathrm{Au}$, for example, can be nucleated onto the tips of nanorods of CdSe and CdS, with the process ostensibly exploiting both the greater reactivity of the strongly curved tips of the dielectric nanorods and the more sparse coverage of protective ligands on the tips of the 
dielectric nanorods compared to their flanks. ${ }^{25}$ The resultant particles have been described as "nanodumbbells'. Precipitating $\mathrm{Au}$ onto a spindle-shaped $\mathrm{Fe}_{2} \mathrm{O}_{3}$ core, possibly with the assistance of an intermediate layer of $\mathrm{SiO}_{2},{ }^{37}$ produces the 'nano-rice' particle, Figure $19 .{ }^{258}$ This has very tunable plasmon resonances because of the ability to independently modify the shape of the spindle core, and the identity, thickness, and morphology of the coinage metal deposited ${ }^{258}$ and can be achieved with Ag too. $^{37}$ In principle, relaxation of the ellipsoidal core geometry $(a=b \neq c$, where $a, b$ and $c$ are the dimensions of the core) to produce a scalene ellipsoid $(a \neq b \neq c)$ coated with Ag should produce the ultimate nanoparticle from the point-of-view of tunability through the visible spectrum. ${ }^{259}$ The three dimensions plus aspect ratio, alloy composition and refractive index of the core, would provide six degrees of freedom by which to tune the resonances across the visible and near-visible spectrum.
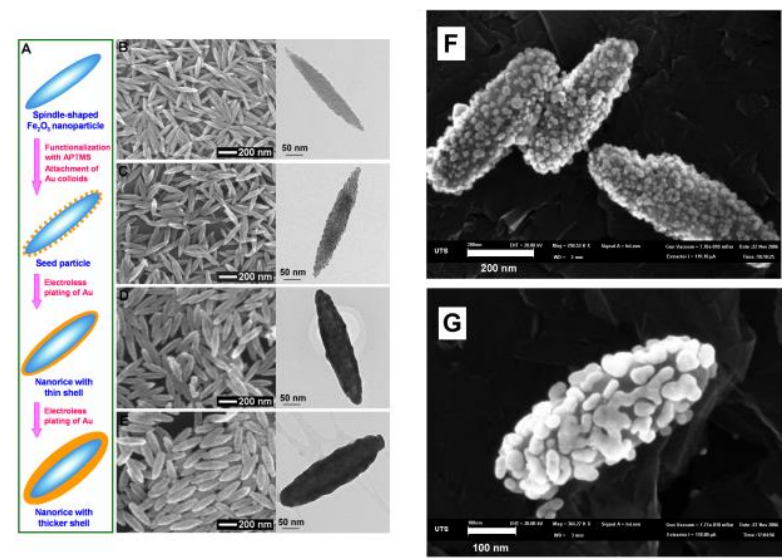

Figure 19. (a) The 'nanorice' hybrid consists of a spindle-shaped dielectric core onto which Au or Ag is deposited. (b) to (e) shows examples of nanorice in various stages of deposition (Reprinted with permission from ref. ${ }^{258}$ Copyright 2007 American Chemical Society.). The process of overcoating can be terminated at any stage to produce a partially coated particle, such as these (f) $\mathrm{Fe}_{2} \mathrm{O}_{3} @ \mathrm{SiO}_{2} @ \mathrm{Ag}$ and (g) $\mathrm{Fe}_{2} \mathrm{O}_{3} @ \mathrm{SiO}_{2} @ \mathrm{Au}$ particles, if desired. (Reprinted with permission from ref. ${ }^{37}$ Copyright 2007 American Chemical Society.).

In another kind of hybrid, thin films of chalcogenide compounds can be formed on noble metal cores, or vice versa, to produce a variety of core-shell nanoparticles. For example, the first synthesis of gold 
nanoshells was prepared from $\mathrm{Au}_{2} \mathrm{~S}$ nanoparticles by partial in situ reduction to form an $\mathrm{Au}$ shell, ${ }^{41,260}$ and there have been several other descriptions of methods to coat noble metal nanoparticle cores with chalcogenide layers such as $\mathrm{Au}_{2} \mathrm{~S}, \mathrm{Ag}_{2} \mathrm{~S}$ or $\mathrm{Ag}_{2} \mathrm{Se}^{44,261}$

There are other reasons for producing 'passive' metal-dielectric hybrids with some optical functionality. The combination of a noble metal nanoparticle and a fluorescent dielectric produces a staining agent for microscopy of biological samples in which the noble metal has the electron density needed for contrast in the electron microscope while an attached fluorescent material provides a signal for optical microscopy. ${ }^{241}$ Fluorescent material (e.g., a CdSe quantum dot) can be attached to or deposited onto a magnetic core to produce a light emitting nanoparticle that can be moved around in biological tissue using an external magnetic field while being observed in a confocal optical microscope. ${ }^{251}$ Heterodimers of $\mathrm{Au}$ and $\mathrm{Fe}_{3} \mathrm{O}_{4}$ can be synthesized for simultaneous optical (due to scattered light from the plasmon resonance of the $\mathrm{Au}$ ) and magnetic imaging. ${ }^{242}$ Controlled aggregation of a hybrid particle comprised of a gold or silver part and a magnetic part can be interrogated in at least three ways: by measuring the shift in the plasmon resonance peak of the coinage metal, or the change in the magnetic signal of the magnetic component, or the increase in dynamic light scattering caused by the aggregated particles. ${ }^{235}$ In principle, the multiplicity of available modes of detection should increase the sensitivity of a sensor or diagnostic stain that uses such hybrids.

\subsection{Active metallo-dielectric hybrids}

\subsubsection{Modulation of plasmon resonance by metal-insulator transitions}

The wavelength and intensity of the plasmon resonance in a nanoparticle is strongly affected by the refractive index in its immediate vicinity. There are a few compounds, such as $\mathrm{VO}_{2}, \mathrm{WO}_{3}, \mathrm{SmS}$ or $\mathrm{NiS}$ for example, ${ }^{262-263}$ that can undergo metal-insulator transitions (and hence transitions in their optical properties) as a function of temperature, composition, redox potential, or pressure. A hybrid 
nanoparticle containing one of these compounds will therefore have a component with a variable refractive index. In particular, $\mathrm{VO}_{2}$ has been investigated for temperature-switchable optical devices. This compound has two forms, a semi-conducting, monoclinic form (' $\mathrm{VO}_{2}-\mathrm{M}_{1}$ '), which is stable at temperatures below about $67^{\circ} \mathrm{C}$, and a metallic, tetragonal structure (' $\mathrm{VO}_{2}-\mathrm{R}$ '), stable above that temperature. The displacive transformation between the two is reversible and attended by large changes in electrical conductivity and optical properties. ${ }^{263-265}$ The idea of combining $\mathrm{VO}_{2}$ with Au to make an active composite nanomaterial with switchable optical properties appears in $1999^{266}$ and the idea of making discrete $\mathrm{VO}_{2} @ \mathrm{Au}$ or $\mathrm{VO}_{2} @ \mathrm{Ag}$ hybrid nanoparticles emerged a few years later. ${ }^{267}$ One attribute of such a particle is that, at certain wavelengths, its optical cross-section drops when heated through the phase transition. This could provide a type of optical limiting effect and possibly even provide temperature control in the nanoparticle, an idea behind the so-called 'regulatron' smart particle, ${ }^{262}$ Figure 20. Unfortunately, no simple chemical process to prepare these hybrids as discrete nanoparticles has been developed yet, although the effect has been experimentally verified for arrays of $\mathrm{Ag}$ or $\mathrm{Au}$ nanoparticles on or in a thin film of $\mathrm{VO}_{2}{ }^{268-269}$ 

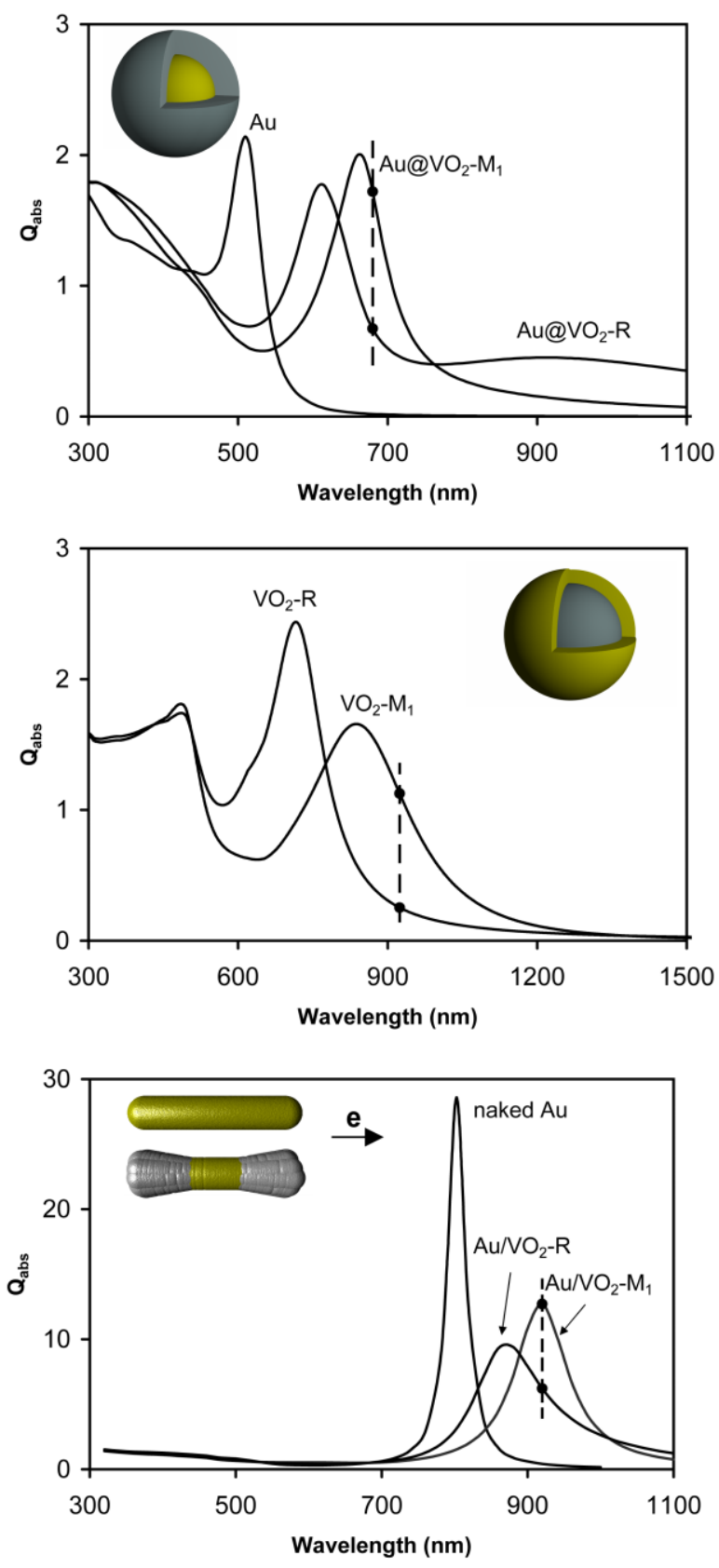

Figure 20. Simulations show that hybrid particles of $\mathrm{Au}$ and $\mathrm{VO}_{2}$ should undergo large changes in optical extinction as a function of the metal to insulator transition in $\mathrm{VO}_{2}$. (a) $\mathrm{Au} @ \mathrm{VO}_{2}$, (b) $\mathrm{VO}_{2} @ \mathrm{Au}$, (c) conceptual hybrid nanorods in which $\mathrm{VO}_{2}$ has been coated onto the ends of an Au nanorods core. Reprinted with permission from ref. ${ }^{262}$ Copyright 2007 American Physical Society.)

\subsubsection{Magnetic hybrids}

We consider here particles in which the magnetic component is used to modulate the optical 
properties through an interaction with the localized electromagnetic field of the plasmon. Such interactions, as in the magneto-optical Kerr and Faraday effects which rotate the plane of polarization of light, have been known in thin films for some time. ${ }^{270}$ Rather different geometries are offered by discrete nanoparticles and studies of these effects are more recent. An 'active' metal-magnet hybrid nanoparticle was reported by $\mathrm{Li}$ et al. in $2005 .{ }^{271}$ In this case $\mathrm{Ag}-\mathrm{CoFe}_{2} \mathrm{O}_{4}$ dimers were formed in colloidal suspension and an enhanced degree of Faraday rotation was observed at some wavelengths indicating that an interaction between the localised surface plasmon of the Ag part and the magnetic material had occurred. Armelles et al. ${ }^{272}$ produced $\mathrm{Au}, \mathrm{Co}, \mathrm{Au}$ sandwiches on a substrate of glass by a combination of nanosphere lithography and physical vapor deposition. The plasmon resonance of the gold was somewhat red-shifted, attenuated and broadened in the hybrid but the most interesting point was that an enhancement of the magnetic-optical effect was observed and ascribed to the effect of the localized plasmon in the gold part. Du et al. ${ }^{273}$ subsequently obtained a similar effect in hybrid nanoparticles comprised of two Au nanodisks at either end of a multilayer $\mathrm{Co} / \mathrm{Pt}$ stack while Jain et al. ${ }^{274}$ have shown that the enhanced magneto-optical activity is possible with $\mathrm{Fe}_{2} \mathrm{O}_{3} @$ Au nanoparticles. The effect is emphasized only at certain wavelengths however, Figure 21. In general, increased rotation of the plane of polarization in these examples required spectral overlap of the magneto-optical transition and a sharp plasmon resonance. There are yet further possibilities for these plasmon-magnetic hybrids with, for example, second harmonic generation recently reported by Murzina et al. ${ }^{275}$ for an Au-Co-Au sandwich particle while Temnov et al. ${ }^{276}$ have recently shown how the propagation of surface plasmon polaritons can be controlled by subjecting a Co layer inserted into an Au waveguide to a magnetic field. This relatively young field of research appears to have much more to offer. 

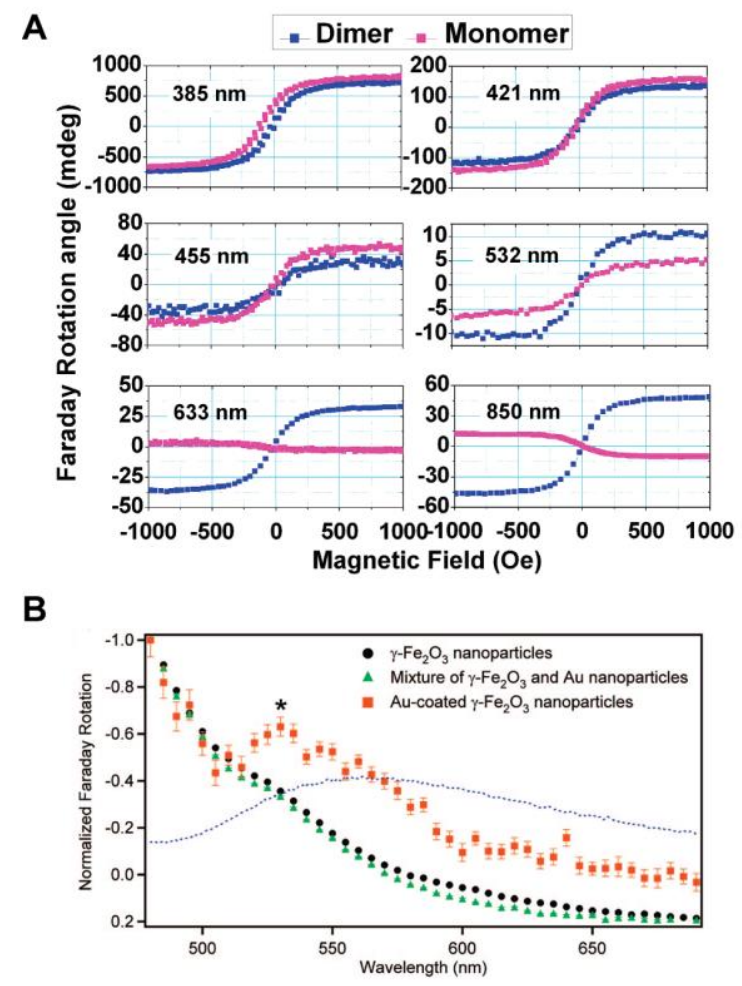

Figure 21. Magneto-optical interaction in hybrid nanoparticles consisting of magnetic material and coinage metal. (a) The Faraday rotation in $\mathrm{Ag} / \mathrm{CoFe}_{2} \mathrm{O}_{4}$ dimers is enhanced for wavelengths $>500 \mathrm{~nm}$, relative to the effect in single nanoparticles. (Reprinted with permission from ref. ${ }^{271}$ Copyright 2005 American Chemical Society.) (b) Some enhancement in Faraday rotation is found in $\mathrm{Fe}_{2} \mathrm{O}_{3} @ \mathrm{Au}$ nanoparticles for wavelengths $>500 \mathrm{~nm}$, relative to a mixture of the individual nanoparticles. (Reprinted with permission from ref. ${ }^{271}$ Copyright 2009 American Chemical Society.)

\subsubsection{Active hybrids with a fluorescent component}

Hybrid particles or nanostructures comprised of a plasmonically resonant part and a fluorescent part were mentioned in Section 3.2 in respect of passive, independent, functionalities. However, the presence of the metal part can have a pronounced effect on the light emission from the fluorescent component, generally attenuating or quenching it ${ }^{25,240,277-279}$ but occasionally enhancing it. ${ }^{280-282}$ The interaction is relatively complex and interesting. A plasmon resonance on the metallic component will have the effect of considerably enhancing the electric field strength around the nanoparticle. This can, in principle, lead 
to enhanced emission from fluorescent molecules or quantum dots located within the region of enhanced field, provided of course that the frequency of the enhanced electric field corresponds with the excitation frequency of the fluorescent substance. However, if the light emitting structure is too close to the metal portion, its excited state may be quenched by transfer of an electron to the metal, which causes the hole to decay non-radiatively in the semi-conductor portion. Which of the effects (enhancement or extinction) will occur depends acutely on the distance between the two components, the temperature, the spatial extent of the electric field and other factors. ${ }^{281}$ It has been proposed that the interplay of these phenomena could be used as the basis of a sensor. ${ }^{281}$

Photoluminescence of a semiconductor generally shows two peaks, a band edge emission and an emission in the mid-visible regime from surface state defects. Depending on application, it may be desired to enhance or suppress the latter. Recently Dimir et al. showed how the surface state emission of a CdS semiconductor nanocrystal could be enhanced twelvefold relative to the band edge emission by deposition onto a layer of Ag nanoparticles. The enhancement mechanism involves coupling between the plasmons in the $\mathrm{Ag}$ and the surface state emissions of the CdS. ${ }^{280}$ This is a highly desirable effect if efficient white light emission is desired. While this is not a true hybrid nanoparticle system as defined earlier, it illustrates that some intriguing effects remain to be explored.

When the energy of an exciton is close to that of a plasmon, then a coherent transfer of energy between the two can occur. ${ }^{281}$ The resulting state has been termed a 'mixed polariton' ${ }^{283}$ and interactions of this type have been reported for various geometric configurations of metal and fluorescent material $^{281,283-284}$ and are an example of a type of metal-enhanced fluorescence. In general these are nonlinear phenomena. ${ }^{25,285}$

Metal-enhanced fluorescence due to amplification of the local electric field is generally absent when the fluorescent material is too close to a metal surface ${ }^{278,286-288}$ and is optimized when the fluorophore is at some intermediate distance of a few tens of nanometers from the surface. ${ }^{289-290}$ The insertion of 'spacer' layers of polymer or some other dielectric such as $\mathrm{SiO}_{2}$ between fluorophore and metal is useful 
to maintain an optimum separation distance. ${ }^{277,291-293}$ Under optimum circumstances, several-fold enhancements in fluorescence have been demonstrated in nanosphere hybrids by this means, Figure $22 .^{281,292}$ The use of a more complex plasmonic structure, for example a sandwich or 'tower' of two Au discs separated by a dielectric and then overcoated with the fluorescent material, has been claimed to provide enhancements in fluorescence of over forty-fold due to the development of a spatially extended electric field around the hybrid nanostructure. ${ }^{60}$

A

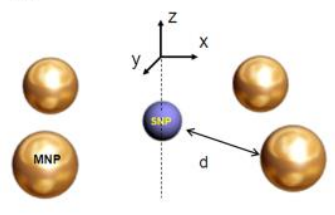

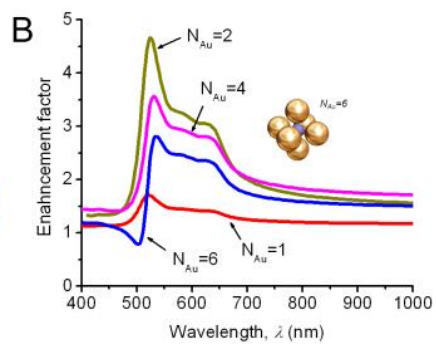

Figure 22. The interaction between metal and fluorescent emitter can lead to quenching or enhancement of the fluorescence. a. The distance, $d$, between emitter and nanoparticle is a key variable. b. Simulations showing how fluorescence enhancements of four or five-fold can be achieved in the most appropriate geometries. (Reprinted with permission from ref. ${ }^{281}$ Copyright 2006 American Chemical Society.).

The quenching effect is often desirable for applications in photocatalysis. In these cases, long-lived separation of the exciton is required so that the hole can provide a site for oxidation and the electron can facilitate reduction. It is possible that the negative charge in this case builds up in the metallic portion slightly faster than it is consumed by reduction reactions, thereby raising the electron density of the metallic region. Since the plasmon resonance frequency of a metal is sensitive to its electron density via the dependence of the bulk plasmon wavelength, $\lambda_{\mathrm{p}}$, on the electron density ${ }^{294}$, it follows that the plasmon resonance wavelength of the metallic nanoparticle can be modulated to some extent by changing its electron density electrochemically, ${ }^{295}$ by depositing a shell of redox-active dielectric onto 
it $^{105}$ or charging with electrons from a nearby excitons. For example, when $\mathrm{Ag} @ \mathrm{TiO}_{2}$ nanoparticles are used as photocatalysts, the plasmon resonance of the Ag blue shifts, which has been interpreted as indicating an increase of electron density in that part of the nanoparticle. ${ }^{296}$

Although the presence of the metal part can quench or enhance the fluorescent emission, the reverse effect, i.e. the exciton exerting an influence on the plasmon, is less well studied. Nevertheless, transfer of energy from exciton to plasmon has been reported ${ }^{291,297}$ although in somewhat larger structures than the hybrid nanoparticles discussed in this review. For example, when $\mathrm{CdS}$ or CdSe quantum dots attached to a $\mathrm{SiO}_{2}$ spacer layer lying in turn on the surface of a $\mathrm{Ag}$ nanowire of several micrometers length were excited, their emitted light coupled to a surface plasmon polariton in the Ag. ${ }^{291,298}$ However, we are not aware of a demonstration of the analogous effect with a localized surface plasmon yet. The interaction between an emitter and a metal nanoparticle has been analyzed theoretically, ${ }^{299-300}$ and found to depend sensitively on the distance between the two. The effect is, however, in general a negative one, in the sense that it removes rather than enhances a functionality (light emission).

Finally, non-linear optical effects have been reported for hybrid nanoparticles of this type. For example, Yang et al reported a significant increase in $\chi^{(3)}$ for films comprised of Au@CdS core-shell particles $^{301}$ and Shaviv et al. found second harmonic emission in Au-CdSe hybrids. ${ }^{302}$

\section{Conclusions and Future Outlook}

Hybrid nanoparticles with two or more components provide significant flexibility in design and application. In this review we have focussed on hybrid systems that display a plasmon resonance in the visible or near-visible regions of the spectrum.

In the hybrid system which we have denoted as 'passive' metallo-dielectric hybrids, the functionalities of the parts remain reasonably independent. Hybrids between a coinage metal $(\mathrm{Cu}, \mathrm{Ag}$, or $\mathrm{Au}$ ) on the one hand and semi-conductors or magnetic oxides on the other frequently fall into this class. The optical properties of these structures may be explained by the properties the individual parts, except 
for some bathochromic shifting of the plasmon resonance of the metallic component due to the increase in local dielectric constant due to the other component.

Metal-metal hybrids and their closely related alloyed nanoparticles exhibit more complex behaviour. The plasmon resonance or resonances of the parts can interact in interesting ways, and can, for example, be enhanced, shifted or suppressed. In the case of core-shell particles, the dielectric properties of the shell material will dominate above some modest thickness and, in the limit, the result is as if the hybrid was comprised throughout of the shell material. This is a fundamentally different result to that obtained in dielectric@coinage metal structures which have a strongly red-shifted plasmon resonance. An important implication of this is that coating a core material that is capable of undergoing plasmon resonance with some other, non-resonant metallic substance, will rapidly destroy any features in the optical spectrum that come from the core plasmon resonance.

Finally, the least understood and possibly most interesting hybrids are those in which the plasmon resonant component interacts in a synergistic manner with the other materials of the hybrid. The plasmon resonance characteristics can be modulated, for example, by a phase change in the other component, or an exciton in a semi-conducting part can be coupled to a plasmon in the metallic part to form a mixed state. These particles appear to offer the prospect of unique new functionalities, such as temperature control, optical limiting or improved photocatalytic properties.

The outlook for hybrid and alloy nanoparticles is promising as they offer the prospect of new or enhanced functionalities. They especially show potential in health technologies, particularly for diagnostic applications, and many of the reports in this field describe quite applied test work. However, as we have documented, hybrid particles may also offer the possibility of breakthrough photocatalysis technology, or as improved non-linear optical materials. There are a great many permutations possible, even if only the metallic elements are considered as ingredients, and of course the possibilities multiply hugely when compounds are considered. The availability of this flexibility provides a platform for the design of some quite sophisticated hybrids, to the extent that some of the more elaborate possibilities 
could be quite justifiably described as individual, functional 'nano-devices'. Examples mentioned here included the 'regulatron', the particle with self-adaptive optical extinction, or the various multifunctional hybrids that can be manipulated with light or magnetism and which can be induced to unload a chemical or thermal payload in response to an external stimulus. There will surely be other, as yet unimagined, functionalities in these hybrid systems, and so there is considerable potential for further research, discovery and exploitation.

Acknowledgement. The authors thank the Australian Research Council for support received from grants DP0666689 and DP0984354. 


\section{Author biographies}

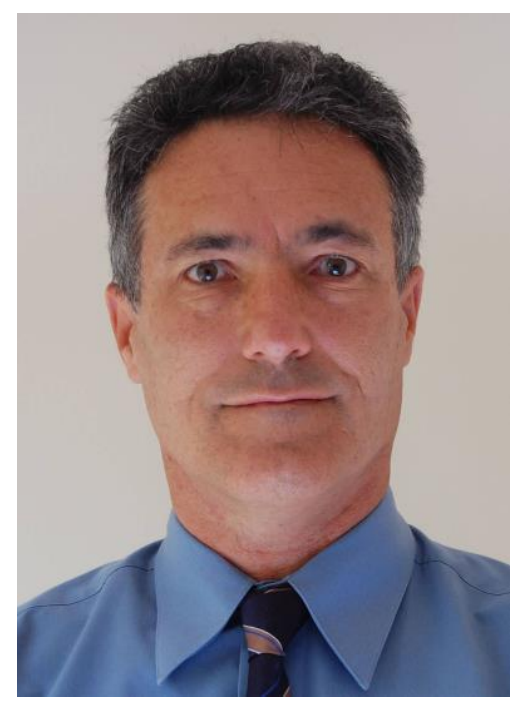

Michael Cortie is Professor of Nanotechnology and Director of the Institute for Nanoscale Technology at the University of Technology Sydney, in Australia. He has a BSc(Engineering) degree in physical metallurgy from the University of the Witwatersrand, South Africa (1978), a Masters in Engineering degree on from the University of Pretoria, South Africa (1983), and a PhD degree on metal fatigue at high temperatures from the University of the Witwatersrand (1987). He joined Mintek, the South African national minerals and metals research organization in 1987. He was a Senior Engineer there before becoming head of its Physical Metallurgy Division between 1997 and 2002. While at Mintek he consulted widely to the international precious metals industry in the areas of nanotechnology, catalysis and physical metallurgy. He relocated to the University of Technology Sydney in July 2002. Michael's main research interests are the nanoparticles and intermetallic compounds of the precious metals, especially as these relate to optical properties. 


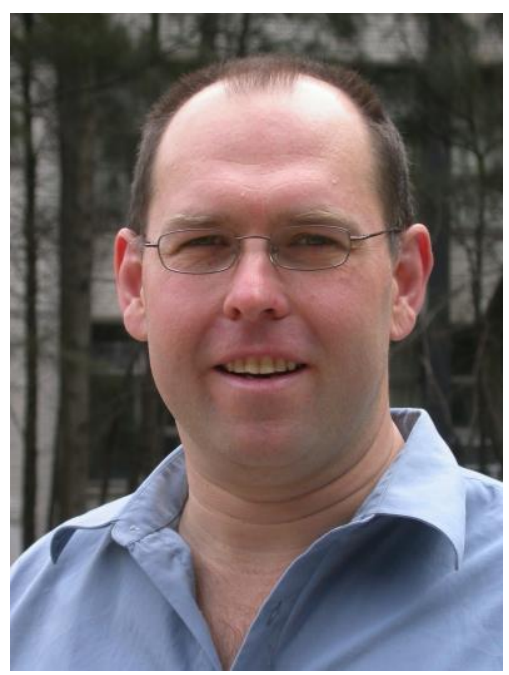

Andrew McDonagh is an Australian Research Council Research Fellow at the University of Technology Sydney, Australia. He received his PhD from the Australian National University in 2000 for studies on the nonlinear optical properties of Group 8 transition metal acetylide complexes (with M. G. Humphrey). He then conducted post-doctoral work at the University of Bristol (with M. D. Ward and J. A. McCleverty) after which he took up a Vice-chancellors Post-doctoral Fellowship at the University of New South Wales, Australia in 2001. He joined the University of Technology Sydney in 2003. His research interests are the synthetic chemistry of particles and inorganic complexes and their applications in surface studies and molecular electronic processes. 


\section{Cover Art}

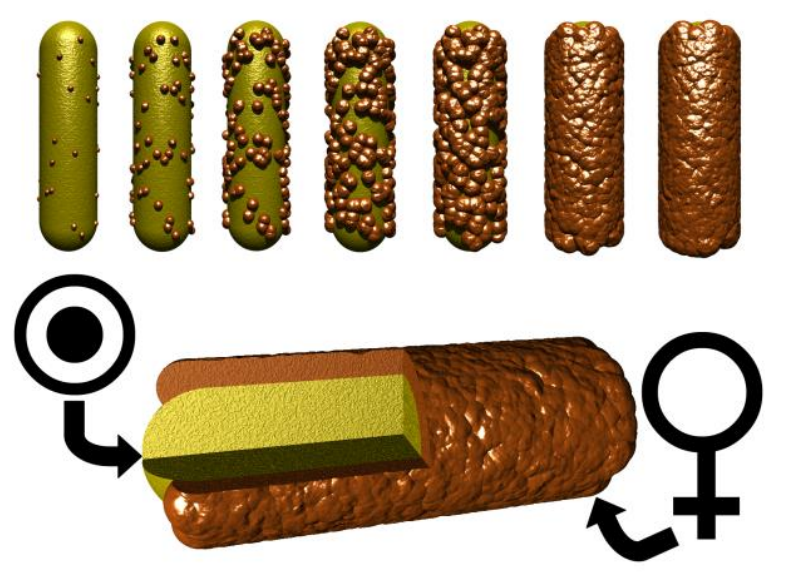

Caption : Schematic illustration of the nucleation and growth of a copper coating on the flanks of a gold nanorod core to produce a hybrid nanoparticle. The symbols are the medieval European representations for $\mathrm{Au}$ and $\mathrm{Cu}$. 


\section{References}

(1) Kelly, K. L.; Coronado, E.; Zhao, L. L.; Schatz, G. C. J. Phys. Chem. B 2003, 107, 668.

(2) Xia, Y.; Halas, N. J. MRS Bulletin 2005, 30, 338.

(3) Xia, Y.; Xiong, Y.; Lim, B.; Skrabalak, S. E. Angew. Chem. Int. Ed. 2009, 48, 60.

(4) Burda, C.; Chen, X.; Narayanan, R.; El-Sayed, M. A. Chem. Rev. 2005, 105, 1025.

(5) Daniel, M.-C.; Astruc, D. Chem. Rev. 2004, 104, 293.

(6) Sardar, R.; Funston, A. M.; Mulvaney, P.; Murray, R. W. Langmuir 2009, 25, 13840.

(7) Perez-Juste, J.; Pastoriza-Santos, I.; Liz-Marzan, L. M.; Mulvaney, P. Coordinat. Chem. Rev. 2005, 249, 1870.

(8) Tréguer-Delapierre, M.; Majimel, J.; Mornet, S.; Duguet, E.; Ravaine, S. Gold Bull. 2008, 41, 195.

(9) Murphy, C. J.; Gole, A. M.; Hunyadi, S. E.; Orendorff, C. J. Inorg. Chem. 2006, 45, 7544.

(10) Blaber, M. G.; Arnold, M. D.; Ford, M. J. J. Phys.: Condens. Matter 2010, 22, 143201.

(11) Ferrando, R.; Jellinek, J.; Johnston, R. L. Chem. Rev. 2008, 108, 846.

(12) Jain, P. K.; Huang, X.; El-Sayed, I. H.; El-Sayed, M. A. Acc. Chem. Res. 2008, 41, 1578.

(13) Schwartzberg, A. M.; Zhang, J. Z. J. Phys. Chem. C 2008, 112, 10323.

(14) Khlebtsov, N. G.; Dykman, L. A. J. Quant. Spectrosc. Radiat. Transfer. 2010, 111, 1.

(15) Pissuwan, D.; Cortie, C. H.; Valenzuela, S. M.; Cortie, M. B. Trends in Biotechnology 2010, 28, 207.

(16) Sperling, R. A.; Gil, P. R.; Zhang, F.; Zanella, M.; Parak, W. J. Chem. Soc. Rev. 2008, 37, 1896.

(17) Wilson, R. Chem. Soc. Rev. 2008, 372028

(18) Stewart, M. E.; Anderton, C. R.; Thompson, L. B.; Maria, J.; Gray, S. K.; Rogers, J. A.; Nuzzo, R. G. Chem. Rev. 2008, 108, 494.

(19) Ghosh, S. K.; Pal, T. Chem. Rev. 2007, 107, 4797.

(20) Iwakoshi, A.; Nanke, T.; Kobayashi, T. Gold Bull. 2005, 38, 107.

(21) Caseri, W. Chem. Eng. Comm. 2009, 196, 549.

(22) Pissuwan, D.; Valenzuela, S. M.; Cortie, M. B. Trends Biotechnol. 2006, 4, 62.

(23) Huang, X.; El-Sayed, I. H.; Qian, W.; El-Sayed, M. A. J. Am. Chem. Soc. 2006, 128, 2115.

(24) Wang, H.; Huff, T. B.; Zweifel, D. A.; He, W.; Low, P. S.; Wei, A.; Cheng, J.-X. Proc. Natl. Acad. Sci. 2005, 102, 15752

(25) Costi, R.; Saunders, A. E.; Banin, U. Angew. Chem. Int. Ed. 2010, 49, 4878.

(26) Katz, E.; Willner, I. Angew. Chem. Int. Ed. 2004, 43, 6042.

(27) Cozzoli, P. D.; Pellegrino, T.; Manna, L. Chem. Soc. Rev. 2006, 351195.

(28) Sanvicens, N.; Marco, M. P. Trends Biotechnol. 2008, 26, 425.

(29) Zeng, H.; Sun, S. H. Adv. Funct. Mater. 2008, 18, 391.

(30) Wang, C.; Xu, C. J.; Zeng, H.; Sun, S. H. Adv. Mater. 2009, 21, 3045.

(31) Zhou, Y.; Wang, C. Y.; Liu, H. J.; Zhu, Y. R.; Chen, Z. Y. Mater. Sci. Eng. B 1999, 67, 95.

(32) Meiklejohn, W. H.; Bean, C. P. Phys. Rev. 1957, 105, 904.

(33) Lee, D. C.; Smith, D. K.; Heitsch, A. T.; Korgel, B. A. Annu. Rep. Prog. Chem., Sect. C 2007, $103,351$.

(34) Kwon, K.-W.; Shim, M. J. Am. Chem. Soc 2005, 127, 10269.

(35) Park, J.; Joo, J.; Kwon, S. G.; Jang, Y.; Hyeon, T. Angew. Chem. Int. Ed. 2007, 46, 4630

(36) Sear, R. P. J. Phys. Chem. B 2006, 110, 4985.

(37) Xu, X.; Cortie, M. B. J. Phys. Chem. C 2007, 111, 18135.

(38) Mokari, T.; Aharoni, A.; Popov, I.; Banin, U. Angew. Chem. Int. Ed. 2006, 45, 8001.

(39) Meyer, R. O. Phys. Rev. 1969, 181, 1086.

(40) Lu, X.; Au, L.; McLellan, J.; Li, Z.-Y.; Marquez, M.; Xia, Y. Nano Lett. 2007, 7, 1764.

(41) Zhou, H. S.; Honma, I.; Komiyama, H.; Haus, J. W. Phys. Rev. B 1994, 50, 12052.

(42) Bao, Z.; Sun, Z.; Xiao, M.; Tian, L.; Wang, J. Nanoscale 2010, 2, 1650.

(43) Ghodselahi, T.; Vesaghi, M. A.; Shafiekhani, A. J. Phys. D: Appl. Phys. 2009, 42, 015308.

(44) Liu, M.; Guyot-Sionnest, P. J. Mater. Chem. 2006, 16, 3942. 
Li, C.; Cai, W.; Kan, C.; Fu, G. Scr. Mater. 2004, 50, 1481.

Schaak, R. E.; Sra, A. K.; Leonard, B. M.; Cable, R. E.; Bauer, J. C.; Han, Y.-F.; Means, J.; Teizer, W.; Vasquez, Y.; Funck, E. S. J. Am. Chem. Soc. 2005, 127, 3506.

Mallin, M. P.; Murphy, C. J. Nano Lett. 2002, 2, 1235.

Link, S.; Wang, Z. L.; El-Sayed, M. A. J. Phys. Chem. B 1999, 103, 3529.

Saunders, A. E.; Popov, I.; Banin, U. Z. Anorg. Allg. Chem. 2007, 633, 2414.

Hulteen, J. C.; Van Duyne, R. P. J Vac Sci Technol A 1995, 13, 1553.

Liu, J.; Maaroof, A. I.; Wieczorek, L.; Cortie, M. B. Adv. Mater. 2005, 17, 1276.

Coutts, M. J.; Zareie, H. M.; Cortie, M. B.; Phillips, M. M.; Wuhrer, R.; McDonagh, A. M. ACS Mater. Interfaces 2010, 2, 1774.

Zareie, H. M.; Morgan, S. W.; Moghaddam, M.; Maaroof, A. I.; Cortie, M. B.; Phillips, M. R. ACS Nano 2008, 2, 1615.

Martin, B. R.; Daniel J. Dermody; Reiss, B. D.; Fang, M.; L. Andrew Lyon; Natan, M. J.; Mallouk, T. E. Adv. Mater. 1999, 11, 1021.

Wang, Y.; Hernandez, R. M.; Bartlett, D. J. J.; Bingham, J. M.; Kline, T. R.; Sen, A.; Mallouk, T. E. Langmuir 2006, 22, 10451.

Kline, T. R.; Tian, M.; Wang, J.; Sen, A.; Chan, M. W. H.; Mallouk, T. E. Inorg. Chem. 2006, 45,7555 .

Nicewarner-Peña, S. R.; Freeman, R. G.; Reiss, B. D.; He, L.; Peña, D. J.; Walton, I. D.; Cromer, R.; Keating, C. D.; Natan, M. J. Science 2001, 294, 137.

Lipomi, D. J.; Kats, M. A.; Kim, P.; Kang, S. H.; Aizenberg, J.; Capasso, F.; Whitesides, G. M. ACS Nano 2010, 4, 4017.

Cortie, M. B.; Giddings, J.; Dowd, A. Nanotechnology 2010, 21, article 115201.

Kravets, V. G.; Zoriniants, G.; Burrows, C. P.; Schedin, F.; Geim, A. K.; Barnes, W. L.; Grigorenko, A. N. Nano Lett. 2010, 10, 874.

Jian, Z.; Yongchang, W.; Yimin, L. Colloids Surf., A 2004, 232, 155.

Papavassiliou, G. C. J. Phys. F: Metal Phys. 1976, 6, L103.

Mancier, V.; Rousse-Bertrand, C.; Dille, J.; Michel, J.; Fricoteaux, P. Ultrason. Sonochem. 2010, 17, 690.

Henglein, A. J. Phys. Chem. B 2000, 104, 2201.

Alayoglu, S.; Nilekar, A. U.; Mavrikakis, M.; Eichhorn, B. Nat. Mater. 2008, 7, 333

Lee, Y. W.; Kim, M.; Kim, Z. H.; Han, S. W. J. Am. Chem. Soc. 2009, 131, 17036.

Yan, J.-M.; Zhang, X.-B.; Akita, T.; Haruta, M.; Xu, Q. J. Am. Chem. Soc. 2010, 132, 5326.

Habas, S. E.; Lee, H.; Radmilovic, V.; Somorjai, G. A.; Yang, P. Nat. Mater. 2007, 6, 692.

Habrioux, A.; Sibert, E.; Servat, K.; Vogel, W.; Kokoh, K. B.; Alonso-Vante, N. J. Phys. Chem. B 2007, 111, 10329.

Bracey, C. L.; Ellis, P. R.; Hutchings, G. J. Chem. Soc. Rev. 2009, 38, 2231.

Bohren, C. F.; Huffman, D. R. Absorption and scattering of light by small particles; Wiley: Weinheim, 2004.

Arnold, M. D.; Blaber, M. G. Optics Express 2009, 17, 3835.

Stokes, N.; McDonagh, A. M.; Cortie, M. B. Gold Bull. 2007, 40, 310.

Hughes, A. E.; Jain, S. C. Adv. Physi. 1979, 28, 717.

Blaber, M. G.; Arnold, M. D.; Harris, N.; Ford, M. J.; Cortie, M. B. Phys. B (Amsterdam, Neth.) 2007, 394, 184.

Cortie, M.; Xu, X.; Ford, M. Phys. Chem. Chem. Phys. 2006, 8, 3520.

Ekinci, Y.; Solak, H. H.; Löffler, J. F. J. Appl. Phys. 2008, 104, 083107.

Quinten, M. J. Cluster Sci. 1999, 10, 321.

Tokonami, S.; Morita, N.; Takasaki, K.; Toshima, N. J. Phys. Chem. C 2010, 114, 10336.

Gonzalez, C. M.; Liu, Y.; Scaiano, J. C. J. Phys. Chem. C 2009, 113, 11861.

Hostetler, M. J.; Zhong, C.-J.; Yen, B. K. H.; Anderegg, J.; Gross, S. M.; Evans, N. D.; Porter, M.; Murray, R. W. J. Am. Chem. Soc. 1998, 120, 9396. 
(82) Lahiri, D.; Bunker, B.; Mishra, B.; Zhang, Z.; Meisel, D.; Doudna, C. M.; Bertino, M. F.; Blum, F. D.; Tokuhiro, A. T.; Chattopadhyay, S.; Shibata, T.; Terry, J. J. Appl. Phys. 2005, 97, 094304.

(83) Murray, J. L. Alloy Phase Diagrams; ASM Materials International: Materials Park, Ohio, 2002.

(84) Bond, G. C. Platinum Metals Rev. 2007, 51, 63.

(85) Xiao, S.; Hu, W.; Luo, W.; Wu, Y.; Li, X.; Deng, H. Eur Phys J B 2006, 54, 479.

(86) Fernandez, C. D.; Mattei, G.; Paz, E.; Novak, R. L.; Cavigli, L.; Bogani, L.; Palomares, F. J.; Mazzoldi, P.; Caneschi, A. Nanotechnology 2010, 21, 165701.

(87) Yasuda, H.; Mori, H. Z. Phys. D 1996, 37, 181.

(88) Jesser, W. A.; Shiflet, G. J.; Allen, G. L.; Crawford, J. L. Mat. Res. Innovat. 1999, 2, 211.

(89) Christensen, A.; Stoltze, P.; Norskov, J. J. Phys.: Condens. Matter 1995, 7, 1047.

(90) Miyajima, K.; Fukushima, N.; Himeno, H.; Yamada, A.; Mafune, F. J. Phys. Chem. A 2009, $113,13448$.

(91) Chatterjee, K.; Howe, J. M.; Johnson, W. C.; Murayama, M. Acta Mat. 2004 52, 2923.

(92) Yang, J.; Lee, J. Y.; Chen, L. X.; Too, H. P. J. Phys. Chem. B 2005, 109, 5468.

(93) Bohren, C. F.; Huffman, D. R. Absorption and Scattering of Light by Small Particles; Wiley: New York, 1998.

(94) Pedersen, D. B.; Wang, S. J. Phys. Chem. C 2007, 111, 17493.

(95) Kim, M.-J.; Na, H.-J.; Lee, K. C.; Yoob, E. A.; Lee, M. J. Mater. Chem. 2003, 13, 1789.

(96) Cattaruzza, E.; Battaglin, G.; Gonella, F.; Polloni, R.; Scremin, B. F.; Mattei, G.; Mazzoldi, P.; Sada, C. Appl. Surf. Sci. 2007, 254, 1017.

(97) Henkel, A.; Jakab, A.; Brunklaus, G.; Sonnichsen, C. J. Phys. Chem. C 2009, 113, 2200.

(98) Morriss, R. H.; Collins, L. F. J. Chem. Phys. 1964, 41, 3357.

(99) Freestone, I.; Meeks, N.; Sax, M.; Higgitt, C. Gold Bull. 2007, 40, 270.

(100) Rodriguez-Gonzalez, B.; Burrows, A.; Watanabe, M.; Kiely, C. J.; Liz-Marzan, L. M. J. Mater. Chem. 2005, 15, 1755.

(101) Ah, C. S.; Hong, S. D.; Jang, D.-J. J. Phys. Chem. B 2001, 105, 7871.

(102) Shi, H.; Zhang, L.; Cai, W. J. Appl. Phys. 2000, 87, 1572.

(103) Shibata, T.; Bunker, B. A.; Zhang, Z.; Meisel, D.; Vardeman II, C. F.; Gezelter, J. D. J. Am. Chem. Soc 2002, 124, 11989.

(104) Peng, Z. Q.; Spliethoff, B.; Tesche, B.; Walther, T.; Kleinermanns, K. J. Phys. Chem. B 2006, $110,2549$.

(105) Mulvaney, P. Langmuir 1996, 12, 788.

(106) Smetana, A. B.; Klabunde, K. J.; Christopher M. Sorensen; Ponce, A. A.; Mwale, B. J. Phys. Chem. B 2006, 110, 2155.

(107) Benten, W.; Nilius, N.; Ernst, N.; Freund, H.-J. Phys. Rev. B 2005, 72, 045403.

(108) Sanchez-Ramirez, J. F.; Pal, U.; Nolasco-Hernandez, L.; J.Mendoza-Alvarez; Pescador-Rojas, J. A. J. Nanomater. 2008, 2008, 620412.

(109) Cattaruzza, E.; Battaglin, G.; Calvelli, P.; Gonella, F.; Mattei, G.; Maurizio, C.; Mazzoldi, P.; Padovani, S.; Polloni, R.; Sada, C.; Scremin, B. F.; D’Acapito, F. Compos. Sci. Technol. 2003, 63, 1203.

(110) Zhang, X.; Tsuji, M.; Lim, S.; Miyamae, N.; Nishio, M.; Hikino, S.; Umezu, M. Langmuir 2007.

(111) Treguer, M.; Cointet, C. d.; Remita, H.; Khatouri, J.; Mostafavi, M.; Amblard, J.; Belloni, J.; Keyzer, R. d. J. Phys. Chem. B 1998, 102, 4310.

(112) Aden, A. L.; Kerker, M. J. Appl. Phys. 1951, 22, 1242.

(113) Mulvaney, P.; Giersig, M.; Henglein, A. J. Phys. Chem. 1993, 97, 7061.

(114) Hodak, J. H.; Henglein, A.; Giersig, M.; Hartland, G. V. J. Phys. Chem. B 2000, 104, 11708.

(115) Belloni, J.; Mostafavi, M.; Remita, H.; Marignier, J.-L.; Delcourt, M.-O. New J. Chem. 1998, 22, 1239.

(116) Hubenthal, F.; Borg, N.; Trager, F. Appl. Phys. B: Lasers Opt. 2008, 93, 39.

(117) Mandal, S.; Selvakannan, P. R.; Pasricha, R.; Sastry, M. J. Am. Chem. Soc. 2003, 125, 8440.

(118) Guerrero-Dib; E., X.; Ortiz-Méndez, U.; Ferrer, D.; Sepúlveda, S.; Jose-Yacaman, M.; 
Kharissova, O. V. Int. J. Green Nanotechnology : Phys. Chem. 2009, 1, 32.

(119) Wilson, O. M.; Scott, R. W. J.; Garcia-Martinez, J. C.; Crooks, R. M. J. Am. Chem. Soc 2005, $127,1015$.

(120) Wang, X.; Zhang, Z.; Hartland, G. V. J. Phys. Chem. B 2005, 109, 20324.

(121) Zhang, Q.; Xie, J.; Lee, J. Y.; Zhang, J.; Boothroyd, C. Small 2008, 8, 1067.

(122) Tsuji, M.; Ogino, M.; Matsunaga, M.; Miyamae, N.; Matsuo, R.; Nishio, M.; Alam, M. J. Cryst. Growth Des. 2010, 10, 4085.

(123) Okuno, Y.; Nishioka, K.; Kiya, A.; Nakashima, N.; Ishibashi, A.; Niidome, Y. Nanoscale 2010, 2, 1489.

(124) Nayak, M. K.; Ghosh, S. K. J. Chem. Phys. 2009, 130, 204702.

(125) Oldenburg, S. J.; Averitt, R. D.; Westcott, S. L.; Halas, N. J. Chem. Phys. Lett. 1998, $288,243$.

(126) Bruzzone, S.; Malvaldi, M.; Arrighini, G. P.; Guidotti, C. J. Phys. Chem. B 2006, 110, 11050.

(127) Vitos, L.; Ruban, A. V.; Skriver, H. L.; Kollar, J. Surf. Sci. 1998, 411, 186.

(128) Metraux, G. S.; Jin, R. C.; Mirkin, C. A. Small 2006, 2, 1335.

(129) Sun, Y.; Xia, Y. J. Am. Chem. Soc. 2004, 126, 3892

(130) Sun, Y.; Xia, Y. Anal. Chem. (Washington, DC, U. S.) 2002, 74, 5297.

(131) Okazaki, K.-i.; Yasui, J.-i.; Torimoto, T. Chem Commun (Camb) 2009, 2917.

(132) Sun, Y.; Xia, Y. Science 2002, 298, 2176.

(133) Jana, N. R.; Gearheart, L.; Murphy, C. J. Adv. Mater. 2001, 13, 1389

(134) Chang, S.-S.; Shih, C.-W.; Chen, C.-D. Langmuir 1999, 15, 701.

(135) Song, J. H.; Kim, F.; Kim, D.; Yang, P. Chem.--Eur. J. s 2005, 11, 910

(136) Liu, M.; Guyot-Sionnest, P. J. Phys. Chem. B 2004, 108(19), 5882.

(137) Becker, J.; Zins, I.; Jakab, A.; Khalavka, Y.; Schubert, O.; Sönnichsen, C. Nano Lett. 2008, 8, 1719.

(138) Okuno, Y.; Nishioka, K.; Nakashima, N.; Niidome, Y. Chem. Lett. 2009, 38, 60.

(139) Sanchez-Iglesias, A.; Carbo-Argibay, E.; Glaria, A.; Rodriguez-Gonzalez, B.; Perez-Juste, J.; Pastoriza-Santos, I.; Liz-Marzan, L. M. Chem.--Eur. J. 2010, 16, 5558.

(140) Kim, Y. J.; Song, J. H. Jap. J. Appl. Phys. 2010, 49.

(141) Huang, Y. F.; Huang, K. M.; Chang, H. T. J. Colloid Interface Sci. 2006, 301, 145.

(142) Cardinal, M. F.; Rodriguez-Gonzalez, B.; Alvarez-Puebla, R. A.; Perez-Juste, J.; Liz-Marzan, L. M. J. Phys. Chem. C 2010, 114, 10417.

(143) Khlebtsov, B. N.; Khanadeev, V. A.; Khlebtsov, N. G. Opt. Spectrosc. 2010, $108,59$.

(144) Duan, J. S.; Park, K.; MacCuspie, R. I.; Vaia, R. A.; Pachter, R. J. Phys. Chem. C 2009, 113, 15524.

(145) Xiang, Y. U.; Wu, X. C.; Liu, D. F.; Li, Z. Y.; Chu, W. G.; Feng, L. L.; Zhang, K.; Zhou, W. Y.; Xie, S. S. Langmuir 2008, 24, 3465.

(146) Xu, X.; Cortie, M. B. Adv. Funct. Mater. 2006, 16, 2170.

(147) Huang, C.-C.; Yang, Z.; Chang, H.-T. Langmuir 2004, $20,6089$.

(148) Park, K.; Vaia, R. A. Adv. Mater. 2008, 20, 3882.

(149) Seo, D.; Song, H. J. Am. Chem. Soc. 2009, 131, 18210.

(150) Yang, Z.; Lin, Y.; Tseng, W.; Chang, H. J. Mater. Chem. 2005, 15, 2450.

(151) Li, M.; Zhang, Z. S.; Zhang, X.; Li, K. Y.; Yu, X. F. Optics Express 2008, 16, 14288.

(152) Tsuji, M.; Miyamae, N.; Lim, S.; Kimura, K.; Zhang, X.; Hikino, S.; Nishio, M. Cryst. Growth Des. 2006, 6, 1801.

(153) Yoo, H. J.; Millstone, J. E.; Li, S. Z.; Jang, J. W.; Wei, W.; Wu, J. S.; Schatz, G. C.; Mirkin, C. A. Nano Lett. 2009, 9, 3038.

(154) Rai, A.; Chaudhary, M.; Ahmad, A.; Bhargava, U.; Sastry, M. Mater. Res. Bull. 2007, 42, 1212.

(155) Chen, H. M.; Hsin, C. F.; Liu, R. S.; Lee, J. F.; Jang, L. Y. J. Phys. Chem. C 2007, 111, 5909.

(156) Ascencio, J. A.; Liu, H. B.; Pal, U.; Medina, A.; Wang, Z. L. Microsc. Res. Tech. 2006, 69, 522.

(157) Sanchez-Ramirez, J. F.; Vazquez, L.; Pal, U. Superficies y vacio 2002, 15, 16.

(158) Sakamoto, M.; Tachikawa, T.; Fujitsuka, M.; Majima, T. Adv. Funct. Mater. 2007, 17, 857. 
(159) Scott, W. R.; Muldawer, L. Phys. Rev. B 1976, 14, 4426.

(160) Banhart, J.; Czycholl, G. Europhys. Lett. 2002, 58, 264.

(161) Meitzner, G.; Via, G. H.; Lytle, F. W.; Sinfelt, J. H. J. Chem. Phys. 1985, 83, 4793.

(162) Cable, R. E.; Schaak, R. E. J. Am. Chem. Soc. 2006, 128, 9588.

(163) Manikandan, D.; Mohan, S.; Nair, K. G. M. Physica B 2003, 337, 64.

(164) Anderson, T. S.; Magruder, R. H. I.; Wittig, J. E.; Kinser, D. L.; Zuhr, R. A. Nucl. Instr. and Meth. in Phys. Res. B 2000, 171, 401.

(165) Langlois, C. T.; Oikawa, T.; Bayle-Guillemaud, P.; Ricolleau, C. J. Nanopart. Res.

2008, 10, 997.

(166) Tsuji, M.; Hikino, S.; Sano, Y.; Horigome, M. Chem. Lett. 2009, 38, 518.

(167) Tsuji, M.; Hikino, S.; Tanabe, R.; Yamaguchi, D. Chem. Lett. 2010, 39, 334.

(168) Tsuji, M.; Hikino, S.; Tanabe, R.; Matsunaga, M.; Sano, Y. CrystEngComm 2010, 12, 3900.

(169) Tsuji, M.; Hikino, S.; Tanabe, R.; Sano, Y. Chem. Lett. 2009, 38, 860.

(170) Howe, J.; Mebed, A.; Chatterjee, K.; Li, P.; Muruyama, M.; Johnson, W. Acta mater. 2003, 51, 1359.

(171) Tabrizi, N. S.; Xu, Q.; Pers, N. M. v. d.; Schmidt-Ott, A. J. Nanopart. Res.

2010, 12, 247.

(172) Pal, S.; Bysakh, S.; De, G. J. Nanosci. Nanotech. 2010, 10, 775.

(173) Belloni, J. Curr. Opin. Colloid Interface Sci. 1996, 1, 184.

(174) Toshima, N.; Harada, M.; Yamazaki, Y.; Asakurat, K. J. Phys. Chem. 1992, 96, 9927.

(175) Lee, A. F.; Baddeley, C. J.; Hardacre, C.; Ormerod, R. M.; Lambert, R. M.; Schmid, G.; West, H. J. Phys. Chem. 1995, 99, 6096.

(176) Harada, M.; Asakura, K.; Toshima, N. J. Phys. Chem. 1993, 97, 5103.

(177) Nutt, M. O.; Hughes, J. B.; Wong, M. S. Environ. Sci. Technol. 2005, 39, 2005, 39, 1346.

(178) Normandeau, G. Gold Bull. 1992, 25, 94.

(179) Xiang, Y. J.; Wu, X. C.; Liu, D. F.; Jiang, X. Y.; Chu, W. G.; Li, Z. Y.; Ma, Y.; Zhou, W. Y.; Xie, S. S. Nano Lett. 2006, 6, 2290.

(180) Camargo, P. H. C.; Xiong, Y.; Ji, L.; Zuo, J. M.; Xia, Y. J. Am. Chem. Soc 2007, 129, 15452.

(181) Mirdamadi-Esfahani, M.; Mostafavi, M.; Keita, B.; Nadjo, L.; Kooyman, P.; Remita, H. Gold Bulletin 2010, 43, 49.

(182) Mandal, S.; Mandale, A. B.; Sastry, M. J. Mater. Chem. 2004, 14, 2868.

(183) Khanal, B. P.; Zubarev, E. R. Angew. Chem., Int. Ed. 2009, 48, 6888.

(184) Guo, S. J.; Wang, L.; Wang, W.; Fang, Y. X.; Wang, E. K. J. Colloid Interface Sci. 2007, 315, 363.

(185) Grzelczak, M.; Perez-Juste, J.; Rodrıguez-Gonzalez, B.; Liz-Marzan, L. M. J. Mater. Chem. 2006, 16, 3946.

(186) Ah, C. S.; Kim, S. J.; Jang, D. J. J. Phys. Chem. B 2006, 110, 5486.

(187) Feng, L. L.; Wu, X. C.; Ren, L. R.; Xiang, Y. J.; He, W. W.; Zhang, K.; Zhou, W. Y.; Xie, S. S. Chem.--Eur. J. 2008, 14, 9764.

(188) He, W. W.; Wu, X. C.; Liu, J. B.; Zhang, K.; Chu, W. G.; Feng, L. L.; Hu, X. A.; Zbou, W. Y.; Me, S. S. J. Phys. Chem. C 2009, 113, 10505.

(189) Yano, K.; Nandwana, V.; Chaubey, G. S.; Poudyal, N.; Kang, S.; Arami, H.; Griffis, J.; Liu, J. P. J. Phys. Chem. C 2009, 113, 13088.

(190) Tierney, M. J.; Martin, C. R. J. Phys. Chem. 1989, 93, 2878.

(191) Paxton, W. F.; Kistler, K. C.; Olmeda, C. C.; Sen, A.; St. Angelo, S. K.; Cao, Y.; Mallouk, T. E.; Lammert, P. E.; Crespi, V. H. J. Am. Chem. Soc 2004, 126, 13424.

(192) Kline, T. R.; Walter F. Paxton; Mallouk, T. E.; Sen, A. Adv. Mater. 1999, 11, No. 12 1999, 11, 1021.

(193) Qin, L.; Banholzer, M. J.; Xu, X.; Huang, L.; Mirkin, C. A. Langmuir 2006, 22, 10451.

(194) Wu, M.-L.; Lai, L.-B. Colloids Surf., A 2004, 244, 149.

(195) Michaelis, M.; Henglein, A.; Mulvaney, P. J. Phys. Chem. B 1994, 98, 6212. 
(196) Kim, S. J.; Ah, C. S.; Jang, D. J. Adv. Mater. 2007, 19, 1064.

(197) Pellegrino, T.; Fiore, A.; Carlino, E.; Giannini, C.; Cozzoli, P. D.; Ciccarella, G.; Respaud, M.; Palmirotta, L.; Cingolani, R.; Manna, L. J. Am. Chem. Soc. 2006, 128, 6690.

(198) Pazos-Pérez, N.; Gao, Y.; Hilgendorff, M.; Irsen, S.; Pérez-Juste, J.; Spasova, M.; Farle, M.; LizMarzán, L. M.; Giersig, M. Chem. Mater. 2007, 19, 4415.

(199) Sobal, N. S.; Hilgendorff, M.; Möhwald, H.; Giersig, M.; Spasova, M.; Radetic, T.; Farle, M. Nano Lett. 2002, 2, 621.

(200) Choi, J.-s.; Jun, Y.-w.; Yeon, S.-I.; Kim, H. C.; Shin, J.-S.; Cheon, J. J. Am. Chem. Soc 2006, $128,15982$.

(201) Gu, H.; Yang, Z.; Gao, J.; Chang, C. K.; Xu, B. J. Am. Chem. Soc 2005, 127, 34.

(202) Zhang, J.; Post, M.; Veres, T.; Jakubek, Z. J.; Guan, J.; Wang, D.; Normandin, F.; Deslandes, Y.; Simard, B. J. Phys. Chem. B 2006, 110, 7122.

(203) Wang, H.; Goodrich, G. P.; Tam, F.; Oubre, C.; Nordlander, P.; Halas, N. J. J. Phys. Chem. B 2005, 109, 11083.

(204) Cortie, M. B.; Ford, M. J. Nanotechnology 2007, 18.

(205) Schotter, J.; Bethge, O.; Maier, T.; Brueckl, H. Appl. Phys. Lett. 2008, 93, 144105.

(206) Zhang, J. Z.; Schwartzberg, A. M.; Norman, T.; Grant, C. D.; Liu, J.; Bridges, F.; Buuren, T. v. Nano Lett. 2005, 5, 809.

(207) Peceros, K. E.; Xu, X.; Bulcock, S. R.; Cortie, M. B. J. Phys. Chem. B 2005, 109, 21516.

(208) Gaudry, M.; Cottancin, E.; Pellarin, M.; Lermé, J.; Arnaud, L.; Huntzinger, J. R.; Vialle, J. L.; Broyer, M.; Rousset, J. L.; Treilleux, M.; Mélinon, P. Phys. Rev. B 2003, 67, 155409.

(209) Kim, C.-C.; Wang, C.; Yang, Y.-C.; Hwu, Y.; Seol, S.-K.; Kwon, Y.-B.; Chen, C.-H.; Liou, H.W.; Lin, H.-M.; Margaritondo, G.; Je, J.-H. Mater. Chem. Phys. 2006, 100, 292.

(210) Grzelczak, M.; Rodríguez-González, B.; Pérez-Juste, J.; Liz-Marzán, L. M. Adv. Mater. 2007, 19, 2262.

(211) Sánchez-Iglesias, A.; Grzelczak, M.; Rodríguez-González, B.; Guardia-Girós, P.; PastorizaSantos, I.; Pérez-Juste, J.; Prato, M.; Liz-Marzán, L. M. ACS Nano 2009, 3, 3184.

(212) Fournier-Bidoz, S.; Arsenault, A. C.; Manners, I.; Ozin, G. A. Chem. Commun. 2005, 441.

(213) Wetz, F.; Soulantica, K.; Falqui, A.; Respaud, M.; Snoeck, E.; Chaudret, B. Angew. Chem. Int. Ed. 2007, 46, 7079

(214) Zhang, Z.; Nenoff, T. M.; Huang, J. Y.; Berry, D. T.; Provencio|, P. P. J. Phys. Chem. C 2009, $113,1155$.

(215) Blaber, M. G.; Arnold, M. D.; Ford, M. J. J. Phys.: Condens. Matter 2009, 21, 144211.

(216) Ferro, R.; Saccone, A.; Macciò, D.; Delfino, S. Gold Bull. 2003, 36, 39.

(217) Pelton, A. D. Bull. Alloy Phase Diagrams 1986, 7, 23.

(218) Pelton, A. D. Bull. Alloy Phase Diagrams 1986, 7, 136.

(219) Supansomboon, S.; Maaroof, A.; Cortie, M. B. Gold Bull. 2008, 41, 296.

(220) Cretu, C.; van der Lingen, E. Gold Bull. 1999, 32, 115.

(221) Boyen, H.-G.; Ethirajan, A.; Kästle, G.; Weigl, F.; Ziemann, P.; Schmid, G.; Garnier, M. G.; Büttner, M.; Oelhafen, P. Phys. Rev. Lett. 2005, 94, 016804.

(222) Chen, L.; Lynch, D. phys. stat. sol. (b) 1988, 148, 387.

(223) Hambrock, J.; Schröter, M. K.; Birkner, A.; Wöll, C.; Fischer, R. A. Chem. Mater 2003, 15, 4217.

(224) Henglein, A.; Mulvaney, P.; Linnert, T.; Holzwarth, A. J. Phys. Chem. 1992, 96, 2411.

(225) Henglein, A.; Giersig, M. J. Phys. Chem. 1994, 98, 6931.

(226) Mulvaney, P.; Giersig, M.; Henglein, A. J. Phys. Chem. 1992, 9610419.

(227) Nadagouda, M. N.; Varma, R. S. Cryst. Growth Des. 2007, 7, 2582.

(228) Yang, L. B.; Shen, Y. H.; Xie, A. J.; Liang, J. J.; Zhu, J. M.; Chen, L. Eur. J. Inorg. Chem. 2007, 1128.

(229) Lu, W.; Wang, B.; Zeng, J.; Wang, X.; Zhang, S.; Hou, J. G. Langmuir 2005, 21, 2005, 21, 3684 . 
(230) Oldfield, G.; Ung, T.; Mulvaney, P. Adv. Mater. 2000, 12, 1519.

(231) Liang, H. P.; Wan, L. J.; Bai, C. L.; Jiang, L. J. Phys. Chem. B 2005, 109, 7795.

(232) Schwartzberg, A. M.; Olson, T. Y.; Talley, C. E.; Zhang, J. Z. J. Phys. Chem. B. 2006, 110, 19935

(233) Liu, J.; Cankurtaran, B.; Wuhrer, R.; Cortie, M. In International Conference on Electronic Materials 2008; International Union of Materials Research Societies: Sydney, Australia, 2008.

(234) Yeo, K. M.; Shin, J.; Lee, I. S. Chem. Commun. 2010, 46, 64.

(235) Choi, S. H.; Bin Na, H.; Il Park, Y.; An, K.; Kwon, S. G.; Jang, Y.; Park, M.; Moon, J.; Son, J. S.; Song, I. C.; Moon, W. K.; Hyeon, T. J. Am. Chem. Soc. 2008, 130, 15573.

(236) Carbone, L.; Jakab, A.; Khalavka, Y.; Sönnichsen, C. Nano Lett. 2009, 9, 3710.

(237) Yang, J.; Levina, L.; Sargent, E. H.; Kelley, S. O. J. Mater. Chem. 2006, 16, 4025.

(238) Yang, J.; Elim, H. I.; Zhang, Q. B.; Lee, J. Y.; Ji, W. J. Am. Chem. Soc. 2006, 128, 11921.

(239) Ding, H.; Shen, C. M.; Hui, C.; Xu, Z. C.; Li, C.; Tian, Y. A.; Shi, X. Z.; Gao, H. J. Chin. Phys. B 2010, 19 .

(240) Shi, W.; Zeng, H.; Sahoo, Y.; Ohulchanskyy, T. Y.; Ding, Y.; Wang, Z. L.; Swihart, M.; Prasad, P. N. Nano Lett. 2006, 6, 875.

(241) Pissuwan, D.; Valenzuela, S. M.; Killingsworth, M. C.; Xu, X.; Cortie, M. B. J. Nanopart. Res. 2007, 9, 1109.

(242) Xu, C.; Xie, J.; Ho, D.; Wang, C.; Kohler, N.; Walsh, E. G.; Morgan, J. R.; Chin, Y. E.; Sun, S. Angew. Chem., Int. Ed. 2008, 47, 173.

(243) Saunders, A. E.; Popov, I.; Banin, U. J. Phys. Chem. B 2006, 110, 25421.

(244) Loo, C.; Lowery, A.; Halas, N.; West, J.; Drezek, R. Nano Lett. 2005, 5, 709.

(245) Hirsch, L.; Gobin, A.; Lowery, A.; F, T.; Drezek, R.; Halas, N.; JL, W. Ann. Biomed. Eng. 2006, $34,15$.

(246) Cole, J. R.; Halas, N. J. Appl. Phys. Lett. 2006, 89, 153120/1

(247) Gobin, A.; Lee, M.-H.; Halas, N. J.; James, W. D.; Drezek, R. A.; West, J. L. Nano Lett. 2007, 7, 1929

(248) Tam, F.; Goodrich, G. P.; Johnson, B. R.; Halas, N. J. Nano Lett. 2007, 7, 496.

(249) Le, F.; Brandl, D. W.; Urzhumov, Y. A.; Wang, H.; Kundu, J.; Halas, N. J.; Aizpurua, J.; Nordlander, P. ACS Nano 2008, 2, 707.

(250) Xu, Z. C.; Hou, Y. L.; Sun, S. H. J. Am. Chem. Soc. 2007, 129, 8698.

(251) Gao, J.; Zhang, W.; Huang, P.; Zhang, B.; Zhang, X.; Xu, B. J. Am. Chem. Soc. 2008, 130, 3710.

(252) Martin, C. R.; Mitchell, D. T. Analytical Chemistry News \& Features 1998, 1st May, 322A.

(253) Elghanian, R.; Storhoff, J. J.; Mucic, R. C.; Letsinger, R. L.; Mirkin, C. A. Science 1997, 277, 1078.

(254) Lin, S.-Y.; Wu, S.-H.; Chen, C.-H. Angew. Chem. Int. Ed. 2006, 45, 4948.

(255) Zhang, J.; Wang, L.; Pan, D.; Song, S.; Boey, F. Y. C.; Zhang, H.; Fan, C. Small 2008, 4, 1196.

(256) Xu, X.; Stevens, M.; Cortie, M. B. Chem. Mater. 2004, 16, 2259.

(257) Ung, T.; Liz-Marzan, L. M.; Mulvaney, P. J. Phys. Chem. B 2001, 105, 3441.

(258) Wang, H.; Brandl, D. W.; Le, F.; Nordlander, P.; Halas, N. J. Nano Lett. 2006, 6, 827.

(259) Kealley, C. S.; Cortie, M. B. Plasmonics 2010, 5, 37.

(260) Averitt, R. D.; Sarkar, D.; Halas, N. J. Phys. Rev. Lett. 1997, 78, 4217.

(261) Zweifel, D. A.; Wei, A. Chem. Mater. 2005, 17, 4256.

(262) Cortie, M. B.; Dowd, A.; Harris, N.; Ford, M. J. Physical Rev. B 2007, 75, 113405.

(263) Mott, N. F. Metal Insulator Transitions; Taylor \& Francis: London, 1974.

(264) Morin, F. J. Phys. Rev. Lett. 1959, 3, 34.

(265) Biermann, S.; Poteryaev, A.; Lichtenstein, A. I.; Georges, A. Phys. Rev. Lett. 2005, 94, 026404

(266) Cavanna, E.; Segaud, J. P.; Livage, J. Mater. Res. Bull. 1999, 34, 167.

(267) Mikheeva, O. P.; Sidorov, A. I. Tech. Phys. 2003, 48, 602.

(268) Suh, J. Y.; Donev, E. U.; Ferrara, D. W.; Tetz, K. A.; Feldman, L. C.; Haglund Jr, R. F. J. Opt. 
A: Pure Appl. Opt. 2008, 10, 055202.

(269) Xu, G.; Huang, C.-M.; Tazawa, M.; Jin, P.; Chen, D.-M. J. Appl. Phys. 2008, 104, 053102.

(270) Safarov, V. I.; Kosobukin, V. A.; Cermann, C.; Lampel, G.; Peretti, J.; Marlière, C. Phys. Rev. Lett. 1994, 73, 3584.

(271) Li, Y.; Zhang, Q.; Nurmikko, A. V.; Sun, S. Nano Lett. 2005, 5, 1689.

(272) González-Díaz, J. B.; García-Martín, A.; García-Martín, J. M.; Cebollada, A.; Armelles, G.; Sepúlveda, B.; Yury Alaverdyan; Käll, M. Small 2008, 4, 202.

(273) Du, G. X.; Mori, T.; Suzuki, M.; Saito, S.; Fukuda, H.; Takahashi, M. Appl. Phys. Lett. $2010,96$.

(274) Jain, P. K.; Xiao, Y. H.; Walsworth, R.; Cohen, A. E. Nano Lett. 2009, 9, 1644.

(275) Murzina, T. V.; Kolmychek, I. A.; Nikulin, A. A.; Gan'shina, E. A.; Aktsipetrov, O. A. Jetp Letters 2009, 90, 504.

(276) Temnov, V. V.; Armelles, G.; Woggon, U.; Guzatov, D.; Cebollada, A.; Garcia-Martin, A.; Garcia-Martin, J. M.; Thomay, T.; Leitenstorfer, A.; Bratschitsch, R. Nat. Phot. 2010, 4, 107.

(277) Pons, T.; Medintz, I. L.; Sapsford, K. E.; Higashiya, S.; Grimes, A. F.; English, D. S.; H.Mattoussi Nano Lett. 2007, 7, 3157.

(278) Shevchenko, E. V.; Ringler, M.; Schwemer, A.; Talapin, D. V.; Klar, T. A.; Rogach, A. L.; Feldmann, J.; Alivisatos, A. P. J. Am. Chem. Soc. 2008, 130, 3274.

(279) Zanella, M.; Falqui, A.; Kudera, S.; Manna, L.; Casula, M. F.; Parak, W. J. J. Mater. Chem. 2008, $18,4311$.

(280) Ozel, T.; Soganci, I. M.; Nizamoglu, S.; Huyal, I. O.; Mutlugun, E.; Sapra, S.; Gaponik, N.; Eychmuller, A.; Demir, H. V. New J. Phys. 2008, 10.

(281) Govorov, A. O.; Bryant, G. W.; Zhang, W.; Skeini, T.; Lee, J.; Kotov, N. A.; Slocik, J. M.; Naik, R. R. Nano Lett. 2006, 6, 984.

(282) Lin, H. Y.; Chen, Y. F.; Wu, J. G.; Wang, D. I.; Chen, C. C. Appl. Phys. Lett. 2006, 88, 161911.

(283) Sugawara, Y.; Kelf, T. A.; Baumberg, J. J.; Abdelsalam, M. E.; Bartlett, P. N. Phys. Rev. Lett. 2006, 97, 266808.

(284) Gómez, D. E.; Vernon, K. C.; Mulvaney, P.; Davis, T. J. Appl. Phys. Lett. 2010, 96, 073108.

(285) Shaviv, E.; Banin, U. ACS Nano 2010, 4, 1529.

(286) Ritchie, G.; Burstein, E. Phys. Rev. B 1981, 24, 4843.

(287) Glass, A. M.; Liao, P. F.; Bergman, J. G.; Olson, D. H. Optics Letters 1980, 5, 368.

(288) Hosoki, K.; Tayagaki, T.; Yamamoto, S.; Matsuda, K.; Kanemitsu, Y. Phys. Rev. Lett. 2008, 100, 207404.

(289) Weber, W. H.; Eagen, C. F. Optics Lett. 1979, 4, 236.

(290) Kümmerlen, J.; Leitner, A.; Brunner, H.; Aussenegg, F. R.; Wokaun, A. Mol. Phys. 1993, 80, 1031.

(291) Fedutik, Y.; Temnov, V. V.; Schops, O.; Woggon, U.; Artemyev, M. V. Phys. Rev. Lett. 2007, 99, 136802.

(292) Aslan, K.; Wu, M.; Lakowicz, J. R.; Geddes, C. D. J. Am. Chem. Soc 2007, 129, 1524.

(293) Park, S. J.; Duncan, T. V.; Sanchez-Gaytan, B. L. J. Phys. Chem. C 2008, 112, 11205.

(294) Mulvaney, P.; Pérez-Juste, J.; Giersig, M.; Liz-Marzán, L. M.; Pecharromán, C. Plasmonics 2006, 1,61 .

(295) Novo, C.; Funston, A. M.; Gooding, A. K.; Mulvaney, P. J. Am. Chem. Soc 2009, 131, 14664.

(296) Hirakawa, T.; Kamat, P. V. J. Am. Chem. Soc 2005, 127, 3928.

(297) Cheng, M.-T.; Liu, S.-D.; Zhou, H.-J.; Hao, Z.-H.; Wang, Q.-Q. Opt. Lett. 2007, 32, 2125.

(298) Wei, H.; Ratchford, D.; Li, X. Q.; Xu, H. X.; Shih, C. K. Nano Lett. 2009, 9, 4168.

(299) Sadeghi, S. M. Nanotechnology 2009, 20, 225401.

(300) Yan, J.-Y.; Zhang, W.; Duan, S.; Zhao, X.-G.; Govorov, A. O. Phys. Rev. B 2008, 77, 165301.

(301) Yang, Y.; Nogami, M.; Shi, J.; Chen, H.; Ma, G.; Tang, S. J. Phys. Chem. B 2005, 109, 4865.

(302) Shaviv, E.; Banin, U. ACS Nano 2010, 4, 1529. 